NBER WORKING PAPER SERIES

\title{
BACKWARD-LOOKING INTEREST-RATE RULES, INTEREST-RATE SMOOTHING, AND MACROECONOMIC INSTABILITY
}

\author{
Jess Banhabib \\ Stephanie Schmitt-Grohé \\ Martín Uribe \\ Working Paper 9558 \\ http://www.nber.org/papers/w9558 \\ NATIONAL BUREAU OF ECONOMIC RESEARCH \\ 1050 Massachusetts Avenue \\ Cambridge, MA 02138 \\ March 2003
}

\begin{abstract}
An earlier version of this paper circulated under the title "Designing Monetary Policy: Backward-Looking Interest-Rate Rules and Interest Rate Smoothing" We thank Chuck Carlstrom, Dale Henderson, and seminar participants at Wharton, Princeton University, NYU, and the Federal Reserve Banks of Philadelphia and Cleveland for comments and Onur Özgür for computational assistance. We are grateful to the C.V. Starr Center of Applied Economics at New York University for technical assistance. Martín Uribe thanks the Federal Reserve Bank of Philadelphia for its hospitality during the writing of this paper. Newer versions of this document are maintained at www.econ.upenn.edu/ uribe. The views expressed herein are those of the authors and not necessarily those of the National Bureau of Economic Research.
\end{abstract}

(C)2003 by Jess Benhabib, Stephanie Schmitt-Grohe, and Martin Uribe. All rights reserved. Short sections of text not to exceed two paragraphs, may be quoted without explicit permission provided that full credit including Cnotice, is given to the source. 
Backward-Looking Interest-Rate Rules, Interest-Rate Smoothing, and Macroeconomic Instability Jess Benhabib, Stephanie Schmitt-Grohé, and Martín Uribe NBER Working Paper No. 9558

March 2003

JEL No. E52, E31, E63

\begin{abstract}
$\underline{\text { ABSTRACT }}$
The existing literature on the stabilizing properties of interest-rate feedback rules has stressed the perils of linking interest rates to forecasts of future inflation. Such rules have been found to give rise to aggregate fluctuations due to self-fulfilling expectations. In response to this concern, a growing literature has focused on the stabilizing properties of interest-rate rules whereby the central bank responds to a measure of past inflation. The consensus view that has emerged is that backwardlooking rules contribute to protecting the economy from embarking on expectations-driven fluctuations. A common characteristic of the existing studies that arrive at this conclusion is their focus on local analysis. The contribution of this paper is to conduct a more global analysis. We find that backward-looking interest-rate feedback rules do not guarantee uniqueness of equilibrium. We present examples in which for plausible parameterizations attracting equilibrium cycles exist. The paper also contributes to the quest for policy rules that guarantee macroeconomic stability globally. Our analysis indicates that policy rules whereby the interest rate is set as a function of the past interest rate and current inflation are likely to ensure global stability provided that the coefficient on lagged interest rates is greater than unity.
\end{abstract}

Jess Benhabib

Department of Economics

New York University

269 Mercer Street

New York NY 10003

jess.benhabib@nyu.edu

Martín Uribe

Department of Economics

The University of Pennsylvania

3718 Locust Walk

Philadelphia PA 19104

and NBER

uribe@econ.upenn.edu
Stephanie Schmitt-Grohé

Department of Economics

Rutgers University

75 Hamilton Street

New Brunswick NJ 08901

and NBER

grohe@econ.rutgers.edu 


\section{Introduction}

In a seminal paper, Taylor (1993) showed that since 1987 actual monetary policy in the United States is well characterized by a simple rule whereby the central bank sets the short-term nominal interest rate as an increasing linear function of a measure of inflation and the output gap, with an inflation coefficient of 1.5. Taylor also provided theoretical arguments for why an inflation coefficient greater than one is conducive to macroeconomic stability. Essentially, his argument is that by raising the nominal interest rate by more than one-for-one in response to an increase in inflation, the central bank in effect raises the real rate of interest. In turn, a higher real interest rate contributes to slowing down domestic absorption, thereby alleviating inflationary pressures.

Taylor's work was followed by a large literature devoted to investigating the desirability of an active monetary policy stance - that is, of interest rate rules with an inflation coefficient greater than one. And by now, a number of studies has cast doubt on the general validity of the finding that active interest-rate feedback rules are stabilizing by pointing out that the stability result is highly dependent on the specifics of the assumed economic environment. For example, Benhabib, SchmittGrohé, and Uribe (2001b), Bernanke and Woodford (1997), and Carlstrom and Fuerst (2000a,b) show that the stability properties of the Taylor criterion depend crucially on the exact definition of the inflation measure to which the central bank responds. Specifically, when the inflation measure consists of forecasts of future expected inflation, then Taylor rules can easily lead to equilibria in which arbitrary changes in agents' expectations about the future path of the economy have real consequences. Of particular importance for the purposes of this paper is that these authors find that by making the inflation measure in the interest rate rule sufficiently backward looking, the central bank can insolate the economy from such self-fulfilling fluctuations.

In this paper we subject the conclusion that active backward-looking interest rate feedback rule are stabilizing to a more rigorous test. Specifically, the literature extant has limited the analysis to characterizing local equilibria in which all endogenous variables remain in a small neighborhood around the intended steady state and are expected to converge to it. By contrast, we study equilibria from a more global perspective. We consider a larger set of equilibria including equilibria in which endogenous variables remain bounded but are never expected to return to the steady state. Our central result is that the existence of such equilibria cannot be ruled out by introducing 
a backward-looking measure of inflation into the Taylor rule. For plausible parameterizations, we show that under active backward-looking rules attracting equilibrium cycles exist. The existence of attracting cycles represents a severe case of policy induced macroeconomic instability. This is because any trajectory originating in a certain relatively large region around the limit cycle, which includes any arbitrarily small neighborhood around the steady state, can be supported as an equilibrium outcome. We demonstrate by means of simulations of calibrated economies that the resulting oscillations are economically significant.

Besides feedback rules that respond to past measures of inflation, there is another large class of interest rate rules that have been identified as both conducive to macroeconomic stability and empirically relevant. The distinctive feature of rules belonging to this class is that the nominal interest rate depends not only on a measure of inflation and the output gap, as in a standard Taylor rule, but also on lagged values of the nominal interest rate itself. Sack (1998), for example, estimates that in U.S. data the coefficient on the lagged interest rate, often referred to as the smoothing coefficient, is about 0.65 and statistically significant. Levin, Wieland, and Williams (1999), Rotemberg and Woodford (1999), and Giannoni and Woodford (2002) advocate interest rate smoothing on theoretical grounds. In particular, Rotemberg and Woodford and Giannoni and Woodford show that rules with a smoothing coefficient that is greater than one guarantee a locally unique equilibrium and are, in addition, capable of implementing the optimal real allocation. The policy recommendation of including lagged interest rates in the rule with a coefficient greater than one has been derived in the context of linear of linearized models. As a result these studies limit attention to equilibria in which all variables are expected to converge in the long-run to the steady state. Uniqueness of equilibrium within this restricted class, however, does not necessarily imply that no other bounded equilibrium exists. The second key contribution of our paper is to apply tools capable of detecting equilibrium cycles to interest rate rules with a smoothing term. We find that if the coefficient on the smoothing term is less than one, then equilibrium cycles exist for plausible parameterizations. On the other hand, if the coefficient on the lagged interest rate is greater than one, then the equilibrium is always locally unique and cyclical equilibria seem unlikely to exist. Comparing these findings with those obtained for backward-looking feedback rules, it follows that the central bank in designing monetary policy should set the current interest rate as a function of past variables, but these past variables should be lagged interest rates (with a coefficient 
greater than one) rather than lagged values of the inflation rate.

The remainder of the paper is organized in 6 sections. Section 2 presents the baseline model. Section 3 characterizes existence and uniqueness of equilibria converging to the steady state. Section 4 shows that under backward-looking interest rate rules equilibrium cycles exist for plausible calibrations. Section 5 shows that under backward-looking interest rate rules equilibrium cycles emerge for a more general class of preference and technology specifications than that considered in section 2. Section 6 studies interest rate smoothing. Finally, section 7 concludes.

\section{The Model}

In this section we describe a simple economy which we will use to evaluate the stabilizing properties of backward-looking interest rate feedback rules. To remain close to the related literature that advocates backward-looking active interest rate feedback rules, we assume that price adjustment is sluggish and that fiscal variables play no role in the determination of prices and inflation.

Some recent theoretical evaluations of monetary policy rules that favor backward-looking behavior on the part of the central bank have restricted attention to models in which variations in the nominal interest rate affect real variables solely through their effect on aggregate demand. Other studies supporting the view that the central bank should set interest rates as a function of past inflation rates have found it more appealing to incorporate the supply side as a prominent channel for the transmission of monetary disturbances. For example, Carlstrom and Fuerst (2000a,b) motivate a demand for money by firms by assuming that wage payments are subject to a cash in advance constraint, and Benhabib, Schmitt-Grohé, and Uribe (2001b) assume that real balances enter directly into the production function. In these papers the introduction of a demand for money by firms is motivated by the fact that in industrialized countries firms hold a substantial fraction of the money supply. For example, in the United States, nonfinancial firms held at least 50 percent more demand deposits than households over the period 1970-1990 (see Mulligan, 1997, and the references cited therein). ${ }^{1}$ In light of this evidence, we follow the strand of the literature that incorporates a supply side channel of monetary policy transmission. We assume, following Fischer (1974), Taylor (1977), and Calvo (1979), that marginal costs of production are increasing in the

\footnotetext{
${ }^{1}$ For empirical evidence on the cost-push effects of interest rates and monetary policy at a disaggregated industry level, see Barth and Ramey (2001).
} 
nominal interest rate because money facilitates firms' production.

\subsection{The household/firm unit}

Assume an economy populated by a continuum of household-firm units indexed by $j$, each of

which produces a differentiated good $Y^{j}$ and faces a demand function $Y^{d} d\left(\frac{P^{j}}{P}\right)$, where $Y^{d}$ denotes the level of aggregate demand, $P^{j}$ the price firm $j$ charges for its output, and $P$ the aggregate price level. Such a demand function can be derived by assuming that households have preferences over a composite good that is produced from differentiated intermediate goods via a Dixit-Stiglitz production function. The function $d(\cdot)$ is assumed to decreasing and to satisfy $d(1)=1$ and $d^{\prime}(1)<-1$. As will become clear shortly, the restriction imposed on $d^{\prime}(1)$ is necessary for the firm's problem to be well defined in a symmetric equilibrium. The production of good $j$ is assumed to take real money balances, $m^{j}$, as the only input

$$
Y^{j}=y\left(m^{j}\right)
$$

where the function $y(\cdot)$ is assumed to be positive, strictly increasing, and strictly concave. The assumption that real balances is the only factor of production is made for analytical convenience. In section 5, we show that the results of this section also hold under a more general production technology that takes labor as well as real balances as factor inputs.

The household's lifetime utility function is assumed to be of the form

$$
U^{j}=\int_{0}^{\infty} e^{-r t}\left[u\left(c^{j}\right)-\frac{\gamma}{2}\left(\frac{\dot{P}^{j}}{P^{j}}-\pi^{*}\right)^{2}\right] d t
$$

where $c^{j}$ denotes consumption of the composite good by household $j$ and $\pi^{*}>-r$ denotes the government's inflation target, which is exogenously given. The utility function $u(\cdot)$ is assumed to be increasing, twice continously differentiable, and strictly concave, and the parameter $\gamma>0$ measures the degree to which household-firm units dislike to deviate in their price-setting behavior from the long-run level of aggregate price inflation. The last term in the instant utility index introduces price stickiness following Rotemberg (1982).

In addition to money, the household can hold nominal bonds, $B$, which pay the nominal interest 
rate $R>0$. Letting $a \equiv(M+B) / P$ denote the household's real financial wealth, $\tau$ real lump-sum taxes, and $\pi \equiv \dot{P} / P$ the inflation rate, the household's instant budget constraint can be written as

$$
\dot{a}^{j}=(R-\pi) a^{j}-R m^{j}+\frac{P^{j}}{P} y\left(m^{j}\right)-c^{j}-\tau .
$$

Household are also assumed to be subject to a no-Ponzi-game constraint of the form

$$
\lim _{t \rightarrow \infty} e^{-\int_{0}^{t}[R(s)-\pi(s)] d s} a^{j}(t) \geq 0
$$

In addition, firms are subject to the constraint that given the price they charge, their sales are demand-determined

$$
y\left(m^{j}\right)=Y^{d} d\left(\frac{P^{j}}{P}\right) .
$$

The household chooses sequences for $c^{j}, m^{j}, P^{j} \geq 0$, and $a^{j}$ so as to maximize (1) subject to (2)-(4) taking as given $a^{j}(0), P^{j}(0)$, and the time paths of $\tau, R, Y^{d}$, and $P$. The Hamiltonian of the household's optimization problem takes the form

$$
\begin{gathered}
e^{-r t}\left\{u\left(c^{j}\right)-\frac{\gamma}{2}\left(\frac{\dot{P}^{j}}{P^{j}}-\pi^{*}\right)^{2}+\lambda^{j}\left[(R-\pi) a^{j}-R m^{j}\right.\right. \\
\left.\left.+\frac{P^{j}}{P} y\left(m^{j}\right)-c^{j}-\tau-\dot{a}^{j}\right]+\mu^{j}\left[Y^{d} d\left(\frac{P^{j}}{P}\right)-y\left(m^{j}\right)\right]\right\} .
\end{gathered}
$$

The first-order conditions associated with $c^{j}, m^{j}, a^{j}$, and $P^{j}$ and the transversality condition are, respectively,

$$
\begin{gathered}
u_{c}\left(c^{j}\right)=\lambda^{j}, \\
\lambda^{j}\left[\frac{P^{j}}{P} y^{\prime}\left(m^{j}\right)-R\right]=\mu^{j} y^{\prime}\left(m^{j}\right), \\
\dot{\lambda^{j}}=\lambda^{j}(r+\pi-R), \\
\lambda^{j} \frac{P^{j}}{P} y\left(m^{j}\right)+\mu^{j} \frac{P^{j}}{P} Y^{d} d^{\prime}\left(\frac{P^{j}}{P}\right)=\gamma r\left(\pi^{j}-\pi^{*}\right)-\gamma \dot{\pi}^{j},
\end{gathered}
$$

and

$$
\lim _{t \rightarrow \infty} e^{-\int_{0}^{t}[R(s)-\pi(s)] d s} a^{j}(t)=0,
$$


where $\pi^{j} \equiv \dot{P}^{j} / P^{j}$

\subsection{The government}

At the center of our analysis is the role played by backward-looking behavior in the conduct of monetary policy. We assume that the central bank follows an interest-rate feedback rule whereby the nominal interest rate is set as an increasing function of an average of past inflation rates. Specifically, we consider the following backward-looking feedback rule

$$
R=\rho\left(\pi^{p}\right) ; \quad \rho^{\prime}>0,
$$

where $\pi^{p}$ is a weighted average of past rates of inflation and is defined as

$$
\pi^{p}=b \int_{-\infty}^{t} \pi(s) e^{b(s-t)} d s ; \quad b>0
$$

The function $\rho(\cdot)$ is assumed to be continuous and non-decreasing. Furthermore, we assume that $\rho\left(\pi^{*}\right)=r+\pi^{*}$. This assumption implies that the government's inflation target can be supported as a steady-state equilibrium. Following Leeper (1991), we refer to monetary policy as active at the inflation target if $\rho^{\prime}\left(\pi^{*}\right)>1$ and as passive if $\rho^{\prime}\left(\pi^{*}\right)<1$. Differentiating (11) with respect to time yields

$$
\dot{\pi}^{p}=b\left(\pi-\pi^{p}\right)
$$

Government purchases are assumed to be zero at all times. Then, the sequential budget constraint of the government is given by $\dot{B}=R B-\dot{M}-P \tau$, which can be written as

$$
\dot{a}=(R-\pi) a-R m-\tau .
$$

Because both the nominal value of initial government liabilities, $A(0)$, and the initial price level, $P(0)$, are predetermined, initial real liabilities of the government, $a(0)=\frac{A(0)}{P(0)}$, are also given.

Government policy is assumed to be of the Ricardian type. Ricardian policies are fiscal-monetary regimes that ensure that the present discounted value of total government liabilities converges to zero - that is, equation (9) is satisfied - under all possible, equilibrium or off-equilibrium, paths of 
endogenous variables such as the price level, the money supply, inflation, or the nominal interest rate. Furthermore, we restrict attention to one particular Ricardian fiscal policy that takes the form

$$
\tau+R m=\alpha a
$$

where the sequence $\alpha$ is chosen arbitrarily by the government subject to the constraint that it is positive. This policy states that consolidated government revenues, that is, tax revenues plus interest savings from the issuance of money, are always equal to a certain positive fraction of total government liabilities. ${ }^{2}$

\subsection{Equilibrium}

In a symmetric equilibrium all household-firm units choose identical sequences for consumption, asset holdings, and prices. As a result, we can drop the superscript $j$. In equilibrium, the goods market must clear. That is,

$$
c=y(m)
$$

Using (15) to eliminate $c$ in (5) yields

$$
u_{c}(y(m))=\lambda
$$

One can then use (16) to express $m$ as a decreasing function of $\lambda .^{3}$

$$
m=m(\lambda) ; \quad m_{\lambda}<0
$$

Let $\eta \equiv d^{\prime}(1)<-1$ denote the equilibrium price elasticity of the demand function faced by the individual firm. Using (6), (15), and (17) to eliminate $m, \mu$, and $c$ from equations (7), (8), (9),

\footnotetext{
${ }^{2} \mathrm{~A}$ special case of this type of policy is a balanced-budget rule whereby tax revenues are equal to interest payments on the debt, which results when $\alpha=R$ (provided $R$ is bounded away from zero). To see that the fiscal policy given by (14) is Ricardian, let $d \equiv \exp \left[-\int_{0}^{t}(R-\pi) d s\right]$ and $x \equiv d a$. The definition of a Ricardian fiscal policy requires that $x \rightarrow 0$ as $t \rightarrow \infty$. Note that $\dot{x}=d[\dot{a}-(R-\pi) a]$. Using equations (13) and (14), this expression can be written as $\dot{x}=-\alpha x$, which implies that $x$ converges monotonically to zero.

${ }^{3}$ Note that by (16) one can find the value of $\lambda$ for any positive value of $m$. However, the converse may not be true, that is, there may exist values of $\lambda$ such that no positive value of $m$ satisfies equation (16). This problem arises when $u_{c}$ or $y($.$) are either bounded above or bounded below away from zero. Observe also that differentiating equation$ (16) implies that $m_{\lambda}=1 /\left[y^{\prime} u_{c c}\right]<0$.
} 
(13), and (14), yields

$$
\begin{aligned}
\dot{\lambda} & =\lambda[r+\pi-R] \\
\gamma \dot{\pi} & =\gamma r\left(\pi-\pi^{*}\right)-y(m(\lambda)) \lambda\left[1+\eta\left(1-\frac{R}{y^{\prime}(m(\lambda))}\right)\right] \\
0 & =\lim _{t \rightarrow \infty} e^{-\int_{0}^{t}[R-\pi] d s} a(t) \\
\dot{a} & =(R-\pi) a-R m(\lambda)-\tau \\
\tau & =-R m(\lambda)+\alpha a
\end{aligned}
$$

To characterize the equilibrium dynamics it is convenient to reduce the system of equilibrium conditions further as follows. First note that given any set of functions $\left\{\pi, \pi^{p}, R, \lambda\right\}$, equations (21) and (22) can be used to construct time paths for $a$ and $\tau$. Because the fiscal policy is Ricardian, the so constructed sequences $\{\pi, a\}$ satisfy the transversality condition (20). Second, use (10) to replace $R$ in (18) and (19). We then have that any set of functions $\left\{\pi, \pi^{p}, \lambda\right\}$, satisfying

$$
\begin{aligned}
\dot{\lambda} & =\lambda\left[r+\pi-\rho\left(\pi^{p}\right)\right] \\
\dot{\pi} & =r\left(\pi-\pi^{*}\right)-\frac{y(m(\lambda)) \lambda}{\gamma}\left[1+\eta\left(1-\frac{\rho\left(\pi^{p}\right)}{y^{\prime}(m(\lambda))}\right)\right] \\
\dot{\pi}^{p} & =b\left(\pi-\pi^{p}\right)
\end{aligned}
$$

given $\pi^{p}(0)$ constitutes a perfect-foresight equilibrium. We summarize this result in the following definition.

Definition 1 (Perfect-foresight equilibrium) A perfect-foresight equilibrium is a set of functions of time $\left\{\lambda, \pi, \pi^{p}\right\}$ satisfying (23)- (25), given $\pi^{p}(0)$.

\section{Equilibria Converging to the Steady State}

Consider first perfect-foresight equilibria in which $\left\{\lambda, \pi, \pi^{p}\right\}$ converge to a steady-state $\left\{\lambda^{*}, \pi^{*}, \pi^{p *}\right\}$. The steady-state values $\lambda^{*}$ and $\pi^{*}$ are defined as constant values of $\lambda, \pi$ and $\pi^{p}$ that solve (23), (24), and (25). Thus, $\pi^{*}$ is a solution to $r+\pi^{*}=\rho\left(\pi^{*}\right)$, which by assumption exists though need not be unique. Given a $\pi^{*}$, we also know $\pi^{p *}$, since $\pi^{p *}=\pi^{*}$. The steady-state value of the marginal utility of consumption, $\lambda^{*}$, is given by the solution to $(1+\eta) / \eta=\rho\left(\pi^{*}\right) / y^{\prime}\left(m\left(\lambda^{*}\right)\right)$. Consider the 
following change of variables. Let $p=\ln \lambda-\ln \lambda^{*}, w=\pi-\pi^{*}$, and $z=\pi^{p}-\pi^{*}$. One steady-state values of $\{p, w, z\}$ is then given by $\left(p^{*}, w^{*}, z^{*}\right)=(0,0,0)$, and the equilibrium conditions can be expressed as

$$
\begin{aligned}
\dot{p} & =r+\pi^{*}+w-\rho\left(z+\pi^{*}\right) \\
\dot{w} & =r w-\frac{y\left(m\left(\lambda^{*} e^{p}\right)\right) \lambda^{*} e^{p} \eta}{\gamma}\left[\frac{1+\eta}{\eta}-\frac{\rho\left(z+\pi^{*}\right)}{y^{\prime}\left(m\left(\lambda^{*} e^{p}\right)\right)}\right] \\
\dot{z} & =b(w-z)
\end{aligned}
$$

In a neighborhood around $\left(p^{*}, w^{*}, z^{*}\right)$, the equilibrium paths of $p, w$, and $z$ converging asymptotically to $\left(p^{*}, w^{*}, z^{*}\right)$ can be approximated by the solutions to the following linearization of (26), (27), and (28) around $\left\{p *, w^{*}, z^{*}\right\}$.

$$
\left(\begin{array}{c}
\dot{p} \\
\dot{w} \\
\dot{z}
\end{array}\right)=A\left(\begin{array}{c}
p-p^{*} \\
w-w^{*} \\
z-z^{*}
\end{array}\right)
$$

where

$$
\begin{aligned}
A & =\left[\begin{array}{ccc}
0 & 1 & -\rho^{\prime} \\
A_{21} & r & A_{23} \\
0 & b & -b
\end{array}\right] \\
A_{21} & =-\frac{\lambda^{* 2} y^{*} \eta R^{*} y^{\prime \prime} m_{\lambda}}{\gamma y^{\prime 2}}>0 \\
A_{23} & =\frac{\lambda^{*} y^{*} \eta}{\gamma} \frac{\rho^{\prime}}{y^{\prime}}<0 .
\end{aligned}
$$

Because $\pi^{p}$ is a non-jump variable and both $\lambda$ and $\pi$ are jump variables, it follows that if $A$ has exactly one root with a negative real part and two roots with positive real parts, then for any $\pi^{p}(0)$ in a small enough neighborhood around $\pi^{*}$, there exists a unique perfect-foresight equilibrium converging to $\left\{\lambda^{*}, \pi^{*}, \pi^{*}\right\}$.

Assume that monetary policy is active $\left(\rho^{\prime}>1\right)$. Then, depending on the value of the parameter $b$, which measures the average lag-length in the inflation measure to which the monetary authority 
responds, the real allocation is either locally determinate or indeterminate. As long as the feedback rule is sufficiently backward looking $(b \rightarrow 0)$, the equilibrium is always unique. To see this, note that when $\rho^{\prime}>1$, the determinant of $A$, which is given by

$$
\operatorname{Det}(A)=b A_{21}\left(1-\rho^{\prime}\right)
$$

is negative. Thus, the number of roots of $A$ with a positive real part is either zero or two. Therefore, equilibrium is either locally unique or indeterminate. If at the same time the trace of $A$ is positive, then the number of roots of $A$ with a positive real part is exactly equal to two. The trace of $A$ is given by

$$
\operatorname{Trace}(A)=r-b
$$

Clearly, as $b$ approaches zero, the trace of $A$ becomes positive. The following proposition summarizes this results and gives further conditions under which equilibrium is locally unique.

Proposition 3.1 Suppose that at the steady state monetary policy is active, that is, $\rho^{\prime}\left(\pi^{*}\right)>1$. If $r+A_{23}>0$ or $b<r$, then there exists a unique competitive equilibrium in which $\lambda$, $\pi$, and $\pi^{p}$ converge to the steady state $\left(\lambda^{*}, \pi^{*}, \pi^{p *}\right)$. If $r+A_{23}<0$ and $b>r$, then depending on the value of $b$, there exist either a continuum or a unique perfect foresight equilibrium, in which $\lambda$, $\pi$, and $\pi^{p}$ converge to the steady state $\left(\lambda^{*}, \pi^{*}, \pi^{p *}\right)$.

Proof: Because the equilibrium system features one non-jump variable $\left(\pi^{p}\right)$ and two jump variables ( $\lambda$ and $\pi$ ), local uniqueness requires that exactly two roots of the matrix $A$ have positive real parts. We have already established that $A$ has either zero or two roots with positive real parts. We apply Routh's theorem (see Gantmacher, 1960) according to which the number of roots of $A$ with positive real parts is equal to the number of variations of sign in the scheme:

$$
-1 \quad \operatorname{Trace}(A) \quad-B+\frac{\operatorname{Det}(\mathrm{A})}{\operatorname{Trace}(A)} \quad \operatorname{Det}(A)
$$

where

$$
B=\text { Sum of the principal minors of } A=-A_{21}-b\left(r+A_{23}\right) \text {. }
$$

This condition implies that in order for no root of $A$ to have a positive real part it is necessary that 
$B$ be positive and that the trace of $A$ be negative. A necessary condition for $B>0$ is $r+A_{23}<0$, and a necessary condition for $\operatorname{trace}(A)<0$ is $b>r$. Thus, whenever $r+A_{23}>0$ or $b<r$, equilibrium is locally unique under active policy. -

Assume now that monetary policy is passive $\left(\rho^{\prime}<1\right)$. Again, as shown in Benhabib, SchmittGrohé, and Uribe (2000) passive backward-looking monetary policy cannot bring about local determinacy. To see this, note that if $\rho^{\prime}<1$, the determinant of $A$ is positive, so the number of roots of $A$ with a negative real part can never be exactly equal to one. If all roots have positive real parts, a perfect-foresight equilibrium in which the real allocation converges to its steady state does not exist. This could be the case for rules that place a lot of weight on the distant past, that is, rules with small $b$ values. On the other hand, if the feedback rule is highly contemporaneous, that is, as $b$ becomes large, the equilibrium is always locally indeterminate. With $b$ large, the trace of $A$ is negative while the determinant remains positive, therefore $A$ must have two roots with negative real parts, implying indeterminacy of equilibrium. These results are summarized in the following proposition.

Proposition 3.2 If monetary policy is passive $\left(\rho^{\prime}\left(\pi^{*}\right)<1\right)$, then there does not exist a unique equilibrium converging to the steady state $\left(\lambda^{*}, \pi^{*},, \pi^{p *}\right)$. Either there exists a continuum of perfectforesight equilibria in which $\lambda, \pi$, and $\pi^{p}$ converge asymptotically to the steady state $\left(\lambda^{*}, \pi^{*},, \pi^{p *}\right)$ or no local equilibrium exists.

Given the above discussion, one may be led to conclude that as long as one follows the Taylor criterion, that is, the nominal interest rate responds by more than one for one to movements in the inflation rate and the measure of inflation to which the central bank responds is sufficiently backward looking, then an active interest rate feedback rule is stabilizing in the sense that it guarantees local uniqueness of the perfect foresight equilibrium. The central contribution of this paper is to show that even in the range of values of $b$ for which the Taylor criterion ensures a unique equilibrium converging to the steady state, other bounded equilibria do exist. In particular, periodic equilibria (endogenous cycles) become possible. 


\section{Equilibria Converging to a Cycle}

Thus far we have restricted attention to perfect-foresight equilibria in which $\left\{\lambda, \pi, \pi^{p}\right\}$ converge asymptotically to $\left\{\lambda^{*}, \pi^{*}, \pi^{p *}\right\}$. We now investigate the existence of perfect-foresight equilibria in which $\lambda, \pi$, and $\pi^{p}$ converge asymptotically to a deterministic cycle. In this case the equilibrium dynamics are still bounded and contained in a neighborhood around the steady state but they do not converge to the steady state. The technical reason why cyclical equilibrium dynamics may arise under active monetary policy is that the system of linear differential equations given in (29) can in this case display a Hopf bifurcation for some critical value of the parameter $b$ describing the average lag-length in the inflation measure used in the interest rate feedback rule. We denote this critical value by $b^{h}$. In turn, the existence of a Hopf bifurcation implies that generically (i.e., if the system is non-linear), there will exist a family of cycles for values of $b$ in a neighborhood located either to the left or to the right of $b^{h}{ }^{4}$ Furthermore, if the cycle is to the left of $b^{h}$ where the steady state is unstable the cycle will be attracting, and the bifurcation is said to be supercritical. The implication is that if the bifurcation is supercritical, then there exist values of $b$ less than $b^{h}$ for which any trajectory $\left\{\lambda, \pi, \pi^{p}\right\}$ that starts out in a neighborhood of $\left\{\lambda^{*}, \pi^{*}, \pi^{p *}\right\}$ will converge to a cycle. Therefore, the perfect foresight equilibrium is indeterminate despite the fact that it is locally unique in the sense described in section 3. The reasons why the indeterminacy of equilibrium identified in this section has been overlooked in the related literature are twofold. First, existing studies have focused on the limiting case in which the nominal interest rate does not affect the cost of production. Second, the majority of previous studies has focused on the dynamics arising from small fluctuations around the steady state that are expected to converge asymptotically to that steady state. Thus, by their very nature, studies of this type are unable to detect equilibria involving bounded fluctuations converging asymptotically to a limit cycle. Readers not interested in the technical details involved in establishing the existence and supercriticality of the Hopf bifurcation may wish to jump directly to the calibration of the model presented at the end of section 4.1 and then jump again to section 4.3, which considers the quantitative aspects of the equilibrium cycles.

\footnotetext{
${ }^{4}$ The Hopf Bifurcation Theorem postulates the existence of a family of cycles, which in the pure linear system pile up at the bifurcation value $b^{h}$ and create a center: any nonlinearity will spread them out to either a left or a right neighborhood of $b^{h}$. Generically, the amplitude of the cycle varies continuously with $b-b^{h}$ and is zero at $b=b^{h}$.
} 


\subsection{Existence of a Hopf Bifurcation}

Formally, a Hopf bifurcation occurs when the real part of two complex roots vanish while the imaginary part does not. A necessary condition for the existence of a Hopf bifurcation in our model is that preferences and technology are such that $r+A_{23}<0 .{ }^{5}$ Otherwise, as we show above, the matrix $A$ has always two roots with positive real parts. Formally, we have the following result.

Proposition 4.1 (Hopf Bifurcation) If monetary policy is active $\left(\rho^{\prime}\left(\pi^{*}\right)>1\right.$ ), and $r+A_{23}<0$, then there exists a unique critical value $b^{h}>0$, such that the dynamical system given in equation (29) displays a Hopf bifurcation. Furthermore, the Hopf bifurcation occurs for $b^{h}>r$.

Proof: Let $C \equiv-B+\frac{\operatorname{Det}(\mathrm{A})}{\operatorname{Trace}(A)}$. Consider the scheme given in equation (32). Note that as $b \rightarrow \infty$ the trace of $A$ becomes negative, $\operatorname{det}(A) / \operatorname{trace}(A)$ converges to a positive constant and $B$ converges to $\infty$. Thus, $C$ converges to $-\infty$ implying a pattern of ---- so that by Routh's Theorem, the matrix $A$ has no root with a positive real part. The function $C$ is monotonically decreasing in $b$, approaches $A_{21}>0$ as $b$ converges to zero and tends to $-\infty$ as $b$ becomes arbitrarily large. At $b=r$, the scalar $C$ is not well defined. When $b$ approaches $r$ from the left, $C$ tends to $-\infty$ and when $b$ approaches $r$ from the right $C \rightarrow \infty$. It follows that there exists a $b>r$ such that the sign pattern in equation (32) shifts from ---- to --+- implying that the real parts of two roots of $A$ change sign from negative to positive as $b$ falls below that critical value. We refer to this critical value of $b$ as $b^{h}$. Note that at $b=b^{h}$, like for any positive values of $b$, the determinant of $A$ is strictly negative. Thus, the two roots that change sign at $b^{h}$ and whose real part vanishes at $b^{h}$ must be complex, else the determinant would also vanish at $b^{h}$. We then have the standard case of a Hopf bifurcation. To see that the system has only one bifurcation, note that for $b$ close to $r$ but below $r$, the sign pattern changes again. This time it changes from --+- to -+-- , However, this change is not associated with a change in the number of roots with positive real parts. As $b$ approaches zero, the pattern changes a last time from -+-- to -++- . Again, this change of sign is not associated with a change in the number of roots with positive real parts.

It follows from the arguments presented in the proof that if monetary policy is active and a Hopf bifurcation exits, then, for all values of $b$ less than the one at which the Hopf bifurcation

\footnotetext{
${ }^{5}$ In the limit, when the inflation measure that enters in the feedback rule approaches current inflation, that is, as $b \rightarrow \infty$, there can exist a Hopf bifurcation exactly at the point where $r+A_{23}=0$, and cycles emerge for $r$ such that $r+A_{23}>0$. For a more detailed discussion see Proposition 7 in Benhabib, Schmitt-Grohé, and Uribe (2001b).
} 
occurs, there exists a unique equilibrium in which the economy converges to the steady state. At the same time, for all values of $b$ greater than the one at which the Hopf bifurcation takes place, there exists a continuum of equilibria converging to the steady state. We summarize this result in the following corollary:

Corollary 4.1 (Local Determinacy) Suppose monetary policy is active $\left(\rho^{\prime}\left(\pi^{*}\right)>1\right.$ ) and $r+$ $A_{23}<0$. If $b<b^{h}$, then there exists a unique competitive equilibrium in which $\lambda, \pi$, and $\pi^{p}$ converge to the steady state $\left(\lambda^{*}, \pi^{*}, \pi^{p *}\right)$. Else, if $b>b^{h}$, then there exists a continuum of competitive equilibria in which $\lambda, \pi$, and $\pi^{p}$ converge to the steady state.

We resort to numerical methods to investigate whether for reasonable parameter values it is indeed the case that $r+A_{23}<0$, so that the dynamical system described by equations (26), (27), and (28) displays a Hopf bifurcation when monetary policy is active. To this end we assume the following functional forms for preference, technology, and the interest rate feedback rule

$$
\begin{aligned}
u(c) & =\frac{c^{1-\sigma}-1}{1-\sigma} ; \quad \sigma>0 \\
y(m) & =\left[\alpha m^{\rho}+(1-\alpha) \bar{y}^{\rho}\right]^{\frac{1}{\rho}} ; \quad \rho<1 \\
\rho\left(\pi^{p}\right) & =R^{*}+D\left(\pi^{p}-\pi^{*}\right) .
\end{aligned}
$$

We calibrate the economy as follows. Let the time unit be a quarter. Let the intended nominal interest rate be 6 percent per year $\left(R^{*}=\ln (1.06) / 4\right)$, which corresponds to the average yield on 3-month U.S. Treasury bills over the period 1960:Q1 to 1998:Q3. We set the target rate of inflation at 4.2 percent per year $\left(\pi^{*}=\ln (1.042) / 4\right)$. This number matches the average growth rate of the U.S. GDP deflator during the period 1960:Q1-1998:Q3. The assumed values for $R^{*}$ and $\pi^{*}$ imply a subjective discount rate of 1.8 percent per year. Following Taylor (1993), we set the elasticity of the interest-rate feedback rule evaluated at $\pi^{*}$ equal to 1.5 (i.e., $\left.\rho^{\prime}\left(\pi^{p *}\right)=D=1.5\right)$. There is a great deal of uncertainty about the value of the intertemporal elasticity of substitution $1 / \sigma$. In the realbusiness-cycle literature, authors have used values as low as 1/3 (e.g., Rotemberg and Woodford, 1992) and as high as 1 (e.g., King, Plosser, and Rebelo, 1988). In the baseline calibration, we assign a value of 2 to $\sigma$. We will also report the sensitivity of the results to variations in the value assumed for this parameter. The value of $\eta$ was chosen so that the implied markup of prices over marginal 
cost at the steady state is 5 percent, which is consistent with the evidence presented by Basu and Fernald (1997). Following Sbordone (2002), we set $\gamma$, the parameter governing the disutility of deviating from the inflation target, at $-17.5(1+\eta)$.

In the steady state, we have by equation (24) that $\frac{1+\eta}{\eta}=\frac{R^{*}}{y^{\prime}\left(m^{*}\right)}$ which for the particular functional forms assumed above gives rise to the following steady-state 'money demand'

$$
m^{*}=R^{* \frac{1}{\rho-1}} y^{*}\left(\frac{\eta}{(1+\eta) \alpha}\right)^{\frac{1}{\rho-1}}
$$

For calibration purposes, we interpret this expression as the long-run money demand function, with a long-run income elasticity of unity and a long-run interest elasticity of $1 /(\rho-1)$. Using U.S. quarterly data from 1960:Q1 to 1999:Q3, we estimate the following money demand function by OLS: 6

$$
\begin{gathered}
\ln m_{t}=0.0446+0.0275 \ln y_{t}-0.0127 \ln \left(\frac{R_{t}}{1+R_{t}}\right)+1.5423 \ln m_{t-1}-0.5918 \ln m_{t-2} \\
t \text {-stat }=(1.8,4.5,-4.7,24.9,-10.0) \\
R^{2}=0.998 ; \quad D W=2.18 .
\end{gathered}
$$

We obtain virtually the same results using instrumental variables. ${ }^{7}$ The short-run log-log elasticity of real balances with respect to its opportunity cost $R_{t} /\left(1+R_{t}\right)$ is -0.0127 , while the long-run elasticity is $-0.2566 .{ }^{8}$ Because the steady-state relation we use to identify the parameter $\rho$ has the interpretation of a long-run money demand equation, we set $\rho$ at -3 , so as to be consistent with the estimated long-run money demand elasticity. Given a value for $\rho$, we can calibrate the parameter

\footnotetext{
${ }^{6}$ We measure $m_{t}$ as the ratio of M1 to the implicit GDP deflator. The variable $y_{t}$ is real GDP in chained 1996 dollars. The nominal interest rate $R_{t}$ is taken to be the quarterly yield on 3-month Treasury bills. Note that in discrete time, the appropriate measure of the opportunity cost of holding money is given by $R_{t} /\left(1+R_{t}\right)$ rather than simply $R_{t}$.

${ }^{7}$ As instruments we choose the first three lags of $\ln y_{t}$ and $\ln R_{t} /\left(1+R_{t}\right)$, and the third and fourth lags of $\ln m_{t}$.

${ }^{8}$ Ball (2002) estimates a long-run money demand equation of the form $\ln m_{t}=\alpha+\theta_{y} \ln y_{t}+\theta_{R} 400 R_{t}+\epsilon_{t}$ using Stock and Watson's (1993) Dynamic OLS Estimator technique with four lags and leads. With a sample of quarterly data from 1959:2 through 1993:4 and measuring the nominal interest rate as the Treasury bill rate, Ball estimates $\theta_{R}$ to be 0.040. Ball's specification implies a long-run log-log interest elasticity of $400 \theta_{R} R=400 \times-0.040 \times(6.10 / 400)=-0.24$, where we used the fact that the average Treasury Bill rate over his sample period was 6.1 percent per year. Ball estimates the long-run money demand equation also with a time series on the rate of return on near-monies that he constructs. These regressions imply a value a log-log interest elasticity of -0.35 .
} 
Table 1: Calibration

\begin{tabular}{|cccccccccc|}
\hline \hline$\eta$ & $\gamma$ & $r$ & $\sigma$ & $\rho$ & $\alpha$ & $\bar{y}$ & $\pi^{*}$ & $R^{*}$ & $\rho^{\prime}\left(\pi^{p *}\right)$ \\
\hline-21 & 350 & 0.0043 & 2 & -3 & 0.0035 & 1 & 0.0103 & 0.0147 & 1.5 \\
\hline \hline
\end{tabular}

Note: The time unit is one quarter.

$\alpha$ of the production function by solving the steady-state 'money demand' equation for $\alpha$ to obtain

$$
\alpha=R^{*} \frac{\eta}{1+\eta}\left(\frac{y^{*}}{m^{*}}\right)^{\rho-1} .
$$

We set $y^{*} / m^{*}=5.8 / 4$ to match the average quarterly U.S. GDP velocity of M1 between 1960:Q1 and 1999:Q3. Given the baseline value of $\rho$, the implied value of $\alpha$ is 0.0035 . Finally, we set the fixed factor $\bar{y}$ at 1 . Table 1 summarizes the calibration of the model.

For this parameterization $r+A_{23}<0$, thus we know that if monetary policy is active, a Hopf bifurcation exists for some $b>r$. In fact, we can compute the exact value of $b$ at which the system bifurcates. For the baseline calibration, the Hopf bifurcation occurs at a value of $b$ equal to 2.736. This value of $b$ implies that the expected lag in the inflation measure is about one month. It follows that for interest rate feedback rules that are less backward looking, equilibrium is locally indeterminate and that for interest rate feedback rules that are more backward looking there exists a unique equilibrium converging to the steady state. However, in the latter case other bounded equilibria may exist. In particular, equilibria in which the economy converges to an attracting cycle. Such cycles are sure to exist when the Hopf bifurcation is supercritical. The next section establishes that this is indeed the case for our baseline calibration.

\subsection{Supercriticality of the Hopf Bifurcation}

To determine whether the Hopf bifurcation is supercritical, we follow closely Yuri A. Kuznetsov's (1998) treatment of bifurcations of equilibria and periodic orbits in n-dimensional dynamical systems. Consider the three dimensional system given by (26), (27), and (28). Letting $x=[p w z]^{\prime}$, we can write that system as

$$
\dot{x}=f(x ; b) ; \quad \text { where } \quad x \in \Re^{3}, b \in \Re^{1} \text {, and } f(0)=0 .
$$


The Jacobian matrix $A$ of this dynamical system is given in equation (29). We have established above that at $b=b^{h}$ and $x=0$, the matrix $A$ has a simple pair of complex eigenvalues on the imaginary axis, $\lambda_{1,2}= \pm i \omega$, with $\omega>0$. Let $q \in C^{3}$ be a complex eigenvector corresponding to $\lambda_{1}$ :

$$
A q=i \omega q, \quad A \bar{q}=-i \omega \bar{q}
$$

where a bar over the eigenvector denotes its complex conjugate. Similarly, let $p \in C^{3}$ be the adjoint eigenvector such that

$$
A^{T} p=-i \omega p, \quad A^{T} \bar{p}=-i \omega \bar{p}
$$

Normalize the eigenvector $q$ so that

$$
<p, q>=1
$$

where $<p, q>=\sum_{i=1}^{n} \bar{p}_{i} q_{i}$.

In order to determine whether the Hopf bifurcation is supercritical we have to compute the first Lyapunov coefficient of the dynamic system (26), (27), and (28) on the center manifold at the critical parameter value $b=b^{h}$ and $x=0$. The first Lyapunov coefficient is given by ${ }^{9}$

$$
l_{1}(0)=\frac{1}{2 \omega} \operatorname{Re}\left[\langle p, C(q, q, \bar{q})\rangle-2\left\langle p, B\left(q, A^{-1} B(q, \bar{q})\right)\right\rangle+\left\langle p, B\left(\bar{q},\left(2 i \omega I_{3}-A\right)^{-1} B(q, q)\right)\right\rangle\right],
$$

where $B(\cdot, \cdot)$ and $C(\cdot, \cdot, \cdot)$ are multilinear functions. In coordinates, the multilinear functions can be written as

$$
B_{i}(x, y)=\left.\sum_{j, k=1}^{n} \frac{\partial^{2} f_{i}(\xi)}{\partial \xi_{j} \partial \xi_{k}}\right|_{\xi=0} x_{j} y_{k}
$$

and

$$
C_{i}(x, y, z)=\left.\sum_{j, k, l=1}^{n} \frac{\partial^{3} f_{i}(\xi)}{\partial \xi_{j} \partial \xi_{k} \partial \xi_{l}}\right|_{\xi=0} x_{j} y_{k} z_{l},
$$

where $i=1,2, \ldots, n$. If $l_{1}(0)<0$, then the Hopf bifurcation is supercritical and a unique stable limit cycle bifurcates from the origin for $b<b^{h} .{ }^{10}$

We do not attempt to evaluate the sign of the first Lyapunov coefficient analytically. Instead we determine its sign numerically for our baseline calibration. To compute the first Lyapunov

\footnotetext{
${ }^{9}$ See Kuznetsov (1998, p. 178).

${ }^{10}$ See Kuznetsov (1998, p. 179).
} 
coefficient we proceed as follows. Note that for the functional forms given in equations (33)-(35), the function $m(\lambda)$ can be written as

$$
m(\lambda)=\left(\frac{\lambda^{-\rho / \sigma}-(1-\alpha) \bar{y}^{\rho}}{\alpha}\right)^{1 / \rho}
$$

We then have an exact analytical expression for the function $f(x)$. We use the Symbolic Math Toolbox of Matlab to find analytical expression for the second- and third-order derivatives of $f$ needed to compute the multilinear functions $B(\cdot, \cdot)$ and $C(\cdot, \cdot, \cdot)$. We then evaluate these expressions at $x=0$ and $b=b^{h}$. In this way, we can obtain a number for $l_{1}(0)$. For our baseline calibration $l_{1}(0)=-11,682$. Thus the Hopf bifurcation is indeed supercritical and attracting cycles exist for $b<b^{h}$.

\subsection{Implied Dynamics}

Figure 1 depicts the phase diagram associated with the equilibrium conditions in the space $\left(\pi_{t}^{p}\right.$, $\left.\ln \left(y_{t} / y^{*}\right), \pi_{t}\right)$. To construct the figure, the policy parameter $b$ was set at 2.5 . This means that the average lag length of inflation to which the central bank responds is about five weeks. ${ }^{11}$ All other parameter values are as shown on table 1. Because the assumed value of $b$ is below the Hopf bifurcation point of 2.74 , the equilibrium system possesses one eigenvalue with a negative real part and two eigenvalues with positive real parts. It follows that for each initial value of the state (no-jump) variable $\pi^{p}$ there is a unique value of $(y, \pi)$ that guarantees that the equilibrium trajectory converges to the steady state. The resulting map from $\pi^{p}$ to $(y, \pi)$, known as the saddle path, is depicted with a broken line in figure 1. The saddle path crosses the steady state, which in the figure is marked with a bullet. But what if the economy were to start slightly off the saddle path? The solid lines illustrates that such trajectories diverge from the saddle path and converge to a limit cycle around the steady state. Along this cycle all variables perpetually fluctuate in an endogenous, deterministic fashion. The limit cycle is attracting. Any initial value of $\left(\lambda, \pi, \pi^{p}\right)$ in a three-dimensional neighborhood around the cycle gives rise to an equilibrium trajectory converging to the cycle. Thus, the equilibrium displays a severe case of indeterminacy.

The amplitude of the endogenous fluctuations shown in figure 1 is significant. To illustrate this,

\footnotetext{
${ }^{11}$ The average lag length of inflation is given by $b \int_{-\infty}^{0} s e^{b s} d s=-1 / b$ quarters.
} 
Figure 1: Endogenous Cycles Under Backward-Looking Taylor Rules: Phase Diagram

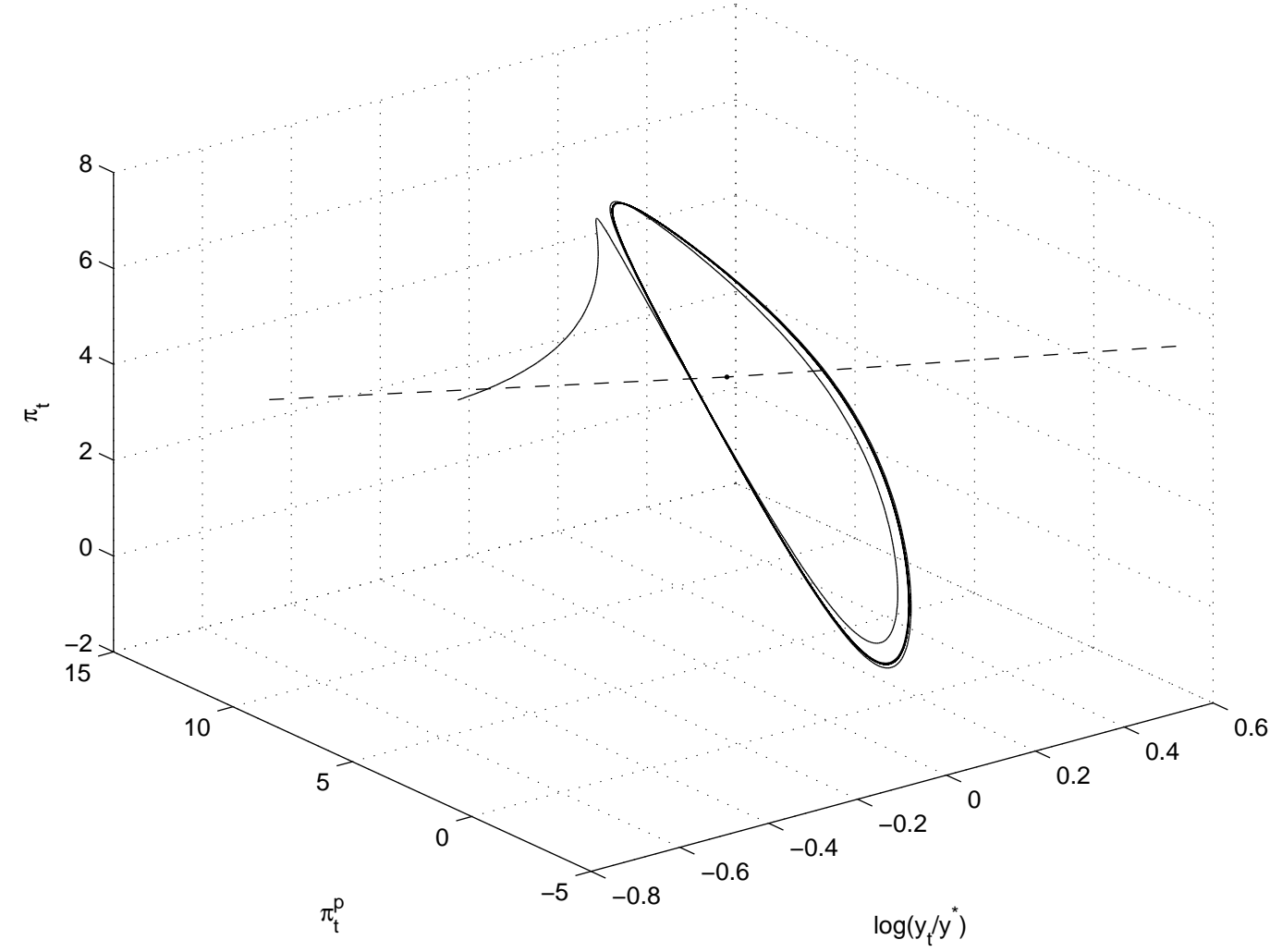

Note: All variables are in percent. Inflation, $\pi_{t}$, and average lagged inflation, $\pi_{t}^{p}$, are expressed in annual rates. The smoothing parameter $b$ is set at 2.5. All other parameter values are as shown in table 1.

figure 2 depicts with a solid line the first 20 quarters of the equilibrium dynamics shown in figure 1. The inflation rate fluctuates between -1.7 and 7.7 percent in annual terms. At the same time, the interest rate displays values as low as 0.4 percent and as high as 12 percent per year. Real output also follows a noticeably fluctuating path - although not so pronounced as those of inflation or the nominal interest rate - with peaks of 0.2 percent above trend and troughs of -0.4 percent below trend. It takes a little over 2 quarters to complete one cycle.

The dotted line in each panel of figure 2 shows the dynamics that would arise in an equilibrium in which the economy starts with the same value for the non-jump variable $\pi^{p}(0)$ as the economy that converges to the cycle, but where the jump variables $\lambda$ and $\pi$ are set such that the economy is initially placed exactly on the saddle path. By construction, the resulting equilibrium trajectory 
Figure 2: Endogenous Cycles Under Backward-Looking Taylor Rules: Time Paths
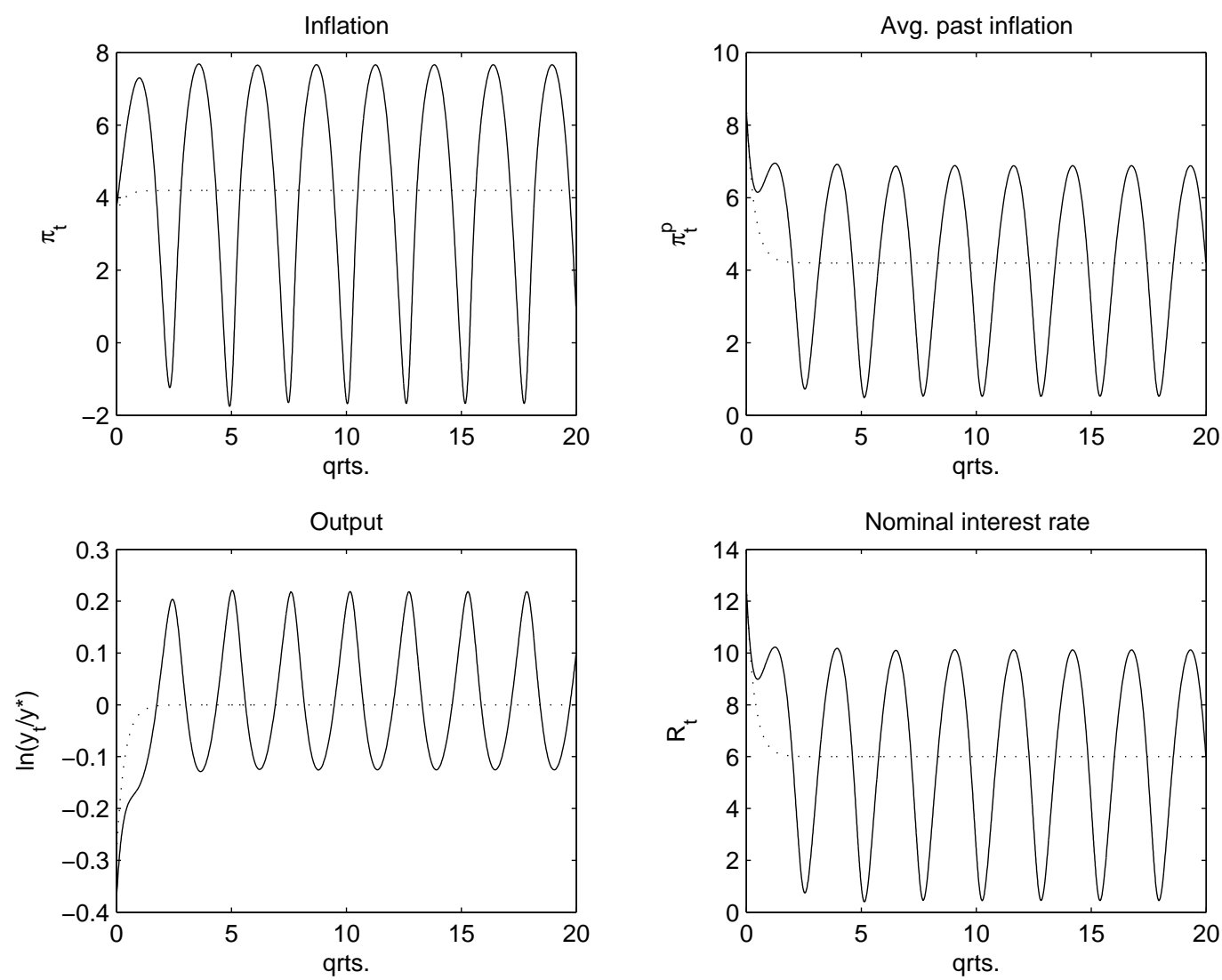

Note: All variables are in percent. Inflation, $\pi_{t}$, and average lagged inflation, $\pi_{t}^{p}$, are expressed in annual rates. The smoothing parameter $b$ is set at 2.5. All other parameter values are as shown in table 1 . The solid line corresponds to equilibria converging to the limit cycle and the dotted line corresponds the equilibrium converging to the steady state.

converges to the steady state. Although the initial value of $\pi^{p}$ is more than four percentage points above its long-run level $\left(\pi^{p}(0)=0.085\right)$ and the initial interest rate is more than six percentage points above target, the economy converges to the steady state with remarkable speed. As can be seen from the figure, after about one quarter the position of the economy is indistinguishable from the steady state. In the standard analysis of the behavior of sticky-price models with interest rate feedback rules, these dynamics would be the only ones investigated and reported.

\subsection{Sensitivity Analysis}

In this section, we explore the robustness of our findings to variations in parameter values. Table 2 
Table 2: Sensitivity Analysis

\begin{tabular}{|c|c|c|c|}
\hline Parameter & $\begin{array}{c}\text { Parameter } \\
\text { value }\end{array}$ & $b^{h}$ & $\begin{array}{c}\text { Hopf bifurcation } \\
\text { is supercritical }\end{array}$ \\
\hline \multirow{5}{*}{$\sigma$} & 1 & 5.47 & yes \\
& $2^{*}$ & 2.74 & yes \\
$\rho$ & -1 & 1.82 & yes \\
\hline \multirow{4}{*}{$\eta$} & $-3^{*}$ & 2.79 & yes \\
& -5 & 3.62 & yes \\
& -3 & 2.1 & yes \\
\hline$\gamma$ & $-21^{*}$ & 2.4 & yes \\
& 1 & 2.74 & yes \\
& $350^{*}$ & 2.73 & yes \\
\hline \multirow{5}{*}{$D$} & 900 & 2.74 & yes \\
& 1.1 & 2.74 & yes \\
\hline$\alpha$ & $1.5^{*}$ & 2.74 & yes \\
& 3 & 2.74 & yes \\
\hline & 0.0018 & 3.23 & yes \\
& $0.0035^{*}$ & 2.73 & yes \\
& 0.007 & 2.29 & yes \\
\hline
\end{tabular}

Note: * indicates the baseline parameter value. $b^{h}$ denotes the value of the parameter $b$ for which the equilibrium displays a Hopf bifurcation. If the Hopf bifurcation is supercritical, then endogenous cycles exist for values of $b$ lower than $b^{h}$ (i.e., for more backward-looking policies than the one associated with $b^{h}$ ). 
displays the value of the parameter $b$ at which the equilibrium presents a Hopf bifurcation. This critical value is denoted by $b^{h}$. The table also indicates whether the Hopf bifurcation is supercritical. Recall that supercriticality of the Hopf bifurcation implies that attracting equilibrium cycles exist for values of $b$ lower than $b^{h}$. That is, for Taylor rules that are more backward-looking than the one associated with $b^{h}$. Recall also that for values of $b$ larger than $b^{h}$ the equilibrium displays local indeterminacy (of order two) because for such values of $b$ all eigenvalues of the Jacobian matrix $A$ have negative real parts. Thus, the smaller is $b^{h}$, the larger is the range of values for the degree of backwardness for which the equilibrium displays some sort of indeterminacy, either in the form of a continuum of equilibria converging to the steady state or in the form of equilibria converging to a cycle. It follows from table 2 that $b^{h}$ tends to decrease as households become more risk averse (large $\sigma$ ), as the money demand elasticity increases ( $\rho$ close to 1 ), as the markup increases ( $\eta$ small in absolute value), and as the share of real balances in the CES production function increases $(\alpha$ large). The value of $b$ at which the Hopf bifurcation occurs is quite insensitive to large variations in the degree of price stickiness. Finally, the bifurcation ceases to be supercritical for highly active Taylor rules.

\section{A Two-Factor Model}

In this section, we consider a generalization of the theoretical model presented in section 2 that allows for endogenous labor supply and assumes that labor in addition to real balances is a factor of production. This specification is of interest because it implies a well-defined equilibrium even in the limiting case in which money balances become unproductive.

Suppose that output is produced via the following production function that takes labor, $h$, and real balances, $m$, as factor inputs

$$
y(m, h)=\left[\alpha m^{\rho}+(1-\alpha)\left(h^{\zeta}\right)^{\rho}\right]^{\frac{1}{\rho}}, \quad \rho<1 \text { and } \zeta \in[0,1]
$$

When the parameter $\zeta$ equals zero, this production function is the same as that presented in equation (34), featuring real balances as the sole factor input. If $\alpha=0$, then the production function is similar to that assumed in most of the related literature, which ignores the productive 
role of money (e.g., Rotemberg and Woodford, 1999; and Clarida, Galí, and Gertler, 1999). ${ }^{12}$ Therefore, the two-factor model presented here encompasses both the baseline model of section 2 and the standard model studied in the related literature.

To introduce endogenous labor supply we consider two alternative forms for the period utility function:

$$
u(c, h)=\frac{c^{1-\sigma}}{1-\sigma}(1-h)^{\xi} ; \quad \sigma>1 \text { and } \xi<0
$$

and

$$
u(c, h)=\frac{c^{1-\sigma}}{1-\sigma}+\frac{1}{\xi}(1-h)^{\xi} ; \quad \sigma, \xi>0,
$$

where $1-h$ denotes the fraction of time devoted to leisure. These specifications of preferences are commonly used in the equilibrium business cycle literature. The household chooses sequences for $c^{j}, h^{j}, m^{j}, P^{j} \geq 0$, and $a^{j}$ so as to maximize

$$
U^{j}=\int_{0}^{\infty} e^{-r t}\left[u\left(c^{j}, h^{j}\right)-\frac{\gamma}{2}\left(\frac{\dot{P}^{j}}{P^{j}}-\pi^{*}\right)^{2}\right] d t
$$

subject to $(3)$,

$$
\dot{a}^{j}=(R-\pi) a^{j}-R m^{j}+\frac{P^{j}}{P} y\left(m^{j}, h^{j}\right)-c^{j}-\tau,
$$

and

$$
y\left(m^{j}, h^{j}\right)=Y^{d} d\left(\frac{P^{j}}{P}\right),
$$

taking as given $a^{j}(0), P^{j}(0)$, and the time paths of $\tau, R, Y^{d}$, and $P$. The Hamiltonian of the household's optimization problem takes the form

$$
\begin{array}{r}
e^{-r t}\left\{u\left(c^{j}, h^{j}\right)-\frac{\gamma}{2}\left(\frac{\dot{P}^{j}}{P^{j}}-\pi^{*}\right)^{2}+\lambda^{j}\left[(R-\pi) a^{j}-R m^{j}\right.\right. \\
\left.\left.+\frac{P^{j}}{P} y\left(m^{j}, h^{j}\right)-c^{j}-\tau-\dot{a}^{j}\right]+\mu^{j}\left[Y^{d} d\left(\frac{P^{j}}{P}\right)-y\left(m^{j}, h^{j}\right)\right]\right\} .
\end{array}
$$

The first-order conditions associated with $c^{j}, h^{j}, m^{j}, a^{j}$, and $P^{j}$ and the transversality condition

\footnotetext{
${ }^{12}$ One can show analytically that in steady state $y \rightarrow h^{\zeta}$ as $\alpha \rightarrow 0$.
} 
are, respectively,

$$
\begin{gathered}
u_{c}\left(c^{j}, h^{j}\right)=\lambda^{j}, \\
-\frac{u_{h}\left(c^{j}, h^{j}\right)}{u_{c}\left(c^{j}, h^{j}\right)}=y_{h}\left(m^{j}, h^{j}\right) \frac{R}{y_{m}\left(m^{j}, h^{j}\right)}, \\
\lambda^{j}\left[\frac{P^{j}}{P} y_{m}\left(m^{j}, h^{j}\right)-R\right]=\mu^{j} y_{m}\left(m^{j}, h^{j}\right), \\
\dot{\lambda^{j}}=\lambda^{j}(r+\pi-R), \\
\lambda^{j} \frac{P^{j}}{P} y\left(m^{j}, h^{j}\right)+\mu^{j} \frac{P^{j}}{P} Y^{d} d^{\prime}\left(\frac{P^{j}}{P}\right)=\gamma r\left(\pi^{j}-\pi^{*}\right)-\gamma \dot{\pi}^{j},
\end{gathered}
$$

and

$$
\lim _{t \rightarrow \infty} e^{-\int_{0}^{t}[R(s)-\pi(s)] d s} a^{j}(t)=0
$$

where $\pi^{j} \equiv \dot{P}^{j} / P^{j}$.

As before, we limit attention to symmetric equilibria, so we drop the superscript $j$. In equilibrium, the goods market must clear. That is,

$$
c=y(m, h)
$$

Combining the resource constraint (48) with (10), (42), and (43), we have that in equilibrium consumption, hours, and real money balances can be expressed in terms of $\lambda$ and $\pi^{p}$. Formally, we have that

$$
\begin{gathered}
c=c\left(\lambda, \pi^{p}\right), \\
h=h\left(\lambda, \pi^{p}\right), \\
m=m\left(\lambda, \pi^{p}\right) .
\end{gathered}
$$

Using these expressions and eliminating the multiplier $\mu$ by means of (44), we can write (45) and (46) as

$$
\begin{gathered}
\dot{\lambda}=\lambda\left(r+\pi-\rho\left(\pi^{p}\right)\right), \\
\dot{\pi}=r\left(\pi-\pi^{*}\right)-\frac{c\left(\lambda, \pi^{p}\right) \lambda}{\gamma}\left\{1+\eta\left[1-\frac{\rho\left(\pi^{p}\right)}{y_{m}\left(m\left(\lambda, \pi^{p}\right), h\left(\lambda, \pi^{p}\right)\right)}\right]\right\} .
\end{gathered}
$$


A competitive equilibrium is then defined as a set of functions of time $\left(\lambda, \pi, \pi^{p}\right)$ satisfying (12), (52), and (53).

Consider first the preference specification given in equation (37), featuring nonseparability in leisure and consumption. In this case, it is straightforward to show that equation (49)-(51) are strict correspondences. That is, for a given pair $\left(\lambda, \pi^{p}\right)$, there exist more than one triplet $(c, h, m)$ that can be supported as an equilibrium outcome. It follows that in this case, equations (12), (52), and (53) represent a system of differential correspondences, whereby for each equilibrium value of the state vector $\left(\lambda, \pi, \pi^{p}\right)$, its rate of change $\left(\dot{\lambda}, \dot{\pi}, \dot{\pi}^{p}\right)$ can take multiple values. Thus, under the first preference specification given above, the economy is subject to instantaneous indeterminacy.

Consider now the second preference specification given in equation (38), featuring additive separability in consumption and leisure. In this case, it can be shown that equations (49)-(51) express the equilibrium values of $(c, h, m)$ as functions (i.e., single-valued correspondences) of $\lambda$ and $\pi^{p}$. Thus, in this case the reduced form of the equilibrium given by (12), (52), and (53) represents a system of (single-valued) differential equations. For the remainder of this section, we therefore focus on the additively separable preference specification.

It turns out that for values of $\xi \neq 1$ and values of $\zeta<1$, there does not exist an explicit representation of $(c, h, m)$ in terms of $\lambda$ and $\pi^{p}$. That is one can at most obtain a system of implicit functions of the form $F(y, x)=0$, where $y=(c, h, m)$ and $x=\left(\lambda, \pi, \pi^{p}\right)$. This feature of the equilibrium conditions complicates a great deal the task of determining the local stability of the steady state, of proving existence of a Hopf bifurcation, and, particularly, of determining the supercriticality of the Hopf bifurcation. For this reason, we assume, as in Hansen (1985) that labor supply is infinitely elastic, $\xi=1$. We also assume that the CES production function (36) is homogeneous of degree one in labor and real balances, $\zeta=1$. In this case, equations (49)-(51) take the following explicit form:

$$
\begin{gathered}
c=c(\lambda) \equiv \lambda^{-1 / \sigma} \\
h=h\left(\lambda, \pi^{p}\right) \equiv c(\lambda)\left[\alpha\left(\frac{\alpha}{1-\alpha} \frac{\xi}{\rho\left(\pi^{p}\right)} c(\lambda)^{\sigma}\right)^{\rho /(1-\rho)}+1-\alpha\right]^{-1 / \rho}
\end{gathered}
$$

and

$$
m=m\left(\lambda, \pi^{p}\right) \equiv h\left(\lambda, \pi^{p}\right)\left[\frac{\alpha \xi c(\lambda)^{\sigma}}{(1-\alpha) \rho\left(\pi^{p}\right)}\right]^{1 /(1-\rho)}
$$


Introducing the change of variable used in section 3 -i.e., $p=\ln \lambda-\ln \lambda^{*}, w=\pi-\pi^{*}$, and $z=\pi^{p}-\pi^{*}$, where $\pi^{*}$ and $\lambda^{*}$ denote the steady-state values of $\pi$ and $\lambda$, respectively-the linearized version of the equilibrium conditions (12), (52), and (53) takes the form given in equations (29) and (30). To evaluate the coefficients of the Jacobian matrix $A$ in this linearized system, we calibrate the economy as follows: The values assigned to $\sigma, \pi^{*}, \eta, \gamma, \rho^{\prime}\left(\pi^{*}\right), R^{*}, \rho$, and GDP velocity are those given in table 1 . The long-run log-log interest elasticity of money is still given by $1 /(\rho-1)$. For this calibration, the element $A_{21}$ of the Jacobian matrix $A$ in equation (30) is positive and element $A_{23}$ is less than $-r$. It follows that the conditions of proposition 4.1 and corollary 4.1 are satisfied. Thus, the equilibrium displays a unique Hopf bifurcation at $b=b^{h}>r$. Furthermore, for values of $b$ less than $b^{h}$ there exists a unique equilibrium converging to the steady state, whereas for $b$ greater than $b^{h}$ there exists a continuum of equilibria converging to the steady state. The value of $b$ at which the Hopf bifurcation occurs is $b^{h}=1.47$ implying that as long as the average lag in the inflation measure to which the central bank responds is longer than 9 weeks, then a unique equilibrium converging to the steady state exists. The central result of our analysis is to show although the equilibrium is locally unique, when $b<b^{h}$, globally the equilibrium can display endogenous aggregate fluctuations in the form of deterministic cycles.

To determine the criticality of the Hopf bifurcation we assume, as before, that the interest rate feedback rule is given by (35), that is, $\rho\left(\pi^{p}\right)=R^{*}+D\left(\pi^{p}-\pi^{*}\right)$. Thus, our calibration implies that $D=1.5$. As in the model without labor, for our calibration the Hopf bifurcation is supercritical. The first Lyapunov coefficient of the dynamic system at the critical parameter value $b=b^{h}$ is -94.47. It follows from the supercriticality of the Hopf bifurcation that for $b<b^{h}$ attracting cycles exist in a neighborhood of $\left(\lambda^{*}, \pi^{*}, \pi^{*}\right)$. Figure 3 depicts the phase diagram associated with the equilibrium conditions in the space $\left(\pi_{t}^{p}, \ln \left(y_{t} / y^{*}\right), \pi_{t}\right)$. In the graph, the average lag in the central bank's inflation measure is about 9 weeks $(b=1.3925)$. Because $b$ is less than $b^{h}$, the equilibrium is saddle-path stable (i.e., there exists a unique equilibrium trajectory converging to the steady state). However, the figure shows that trajectories starting off the saddle path may converge to an equilibrium cycle around the steady state. Thus, like in the model without labor, equilibrium displays a severe case of indeterminacy. ${ }^{13}$

\footnotetext{
${ }^{13}$ Recall that for values of $b$ greater than $b^{h}$, the equilibrium system possesses three roots with negative real parts. This means that for these values of $b$, there exists a continuum of equilibria converging to the steady state.
} 
Figure 3: Two-Factor Model: Endogenous Cycles Under Backward-Looking Taylor Rules

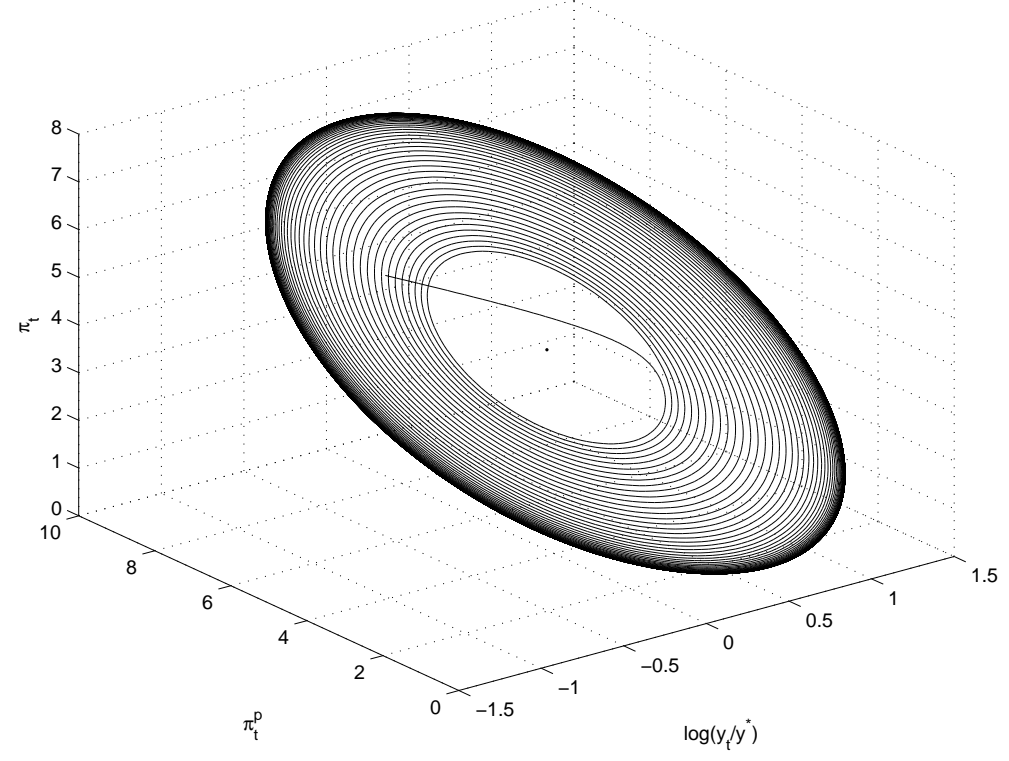

Note: All variables are in percent. Inflation, $\pi_{t}$, and average lagged inflation, $\pi_{t}^{p}$, are expressed in annual rates. The smoothing parameter $b$ is set at 1.3925 (about 9 weeks) and the remaining parameters take the values shown in table 1.

Figure 4 shows the time path of a trajectory converging to the limit cycle. The cycle has a frequency of about 8 years and features inflation rates fluctuating between 0.5 and 8 percent per year. Along the limiting cycle the nominal interest rate varies between 0.5 and 12 percent per year. Aggregate activity peaks at 1.4 percent above trend and bottoms out at 1.3 percent below trend.

A natural question that arises from the above analysis is whether cycles exist for highly backward-looking interest-rate rules, that is, for $b$ close to zero. Given our calibration of all other parameter values, the smallest value of $b$ for which we could numerically detect the existence of economically meaningful cycles is 1.36 . Below this value of $b$, cycles continue to exist but become economically irrelevant, as they violate the zero lower bound on the nominal interest rate. Our next step is therefore to consider interest rate rules that respect this non-negativity constraint. Specifically, we analyze the existence of endogenous equilibrium cycles under an interest-rate feedback rule of the form

$$
R=\rho\left(\pi^{p}\right) \equiv R^{*} \exp \left[\frac{D}{R^{*}}\left(\pi^{p}-\pi^{*}\right)\right]
$$


Figure 4: Two-Factor Model: Time Paths of Equilibrium Cycles
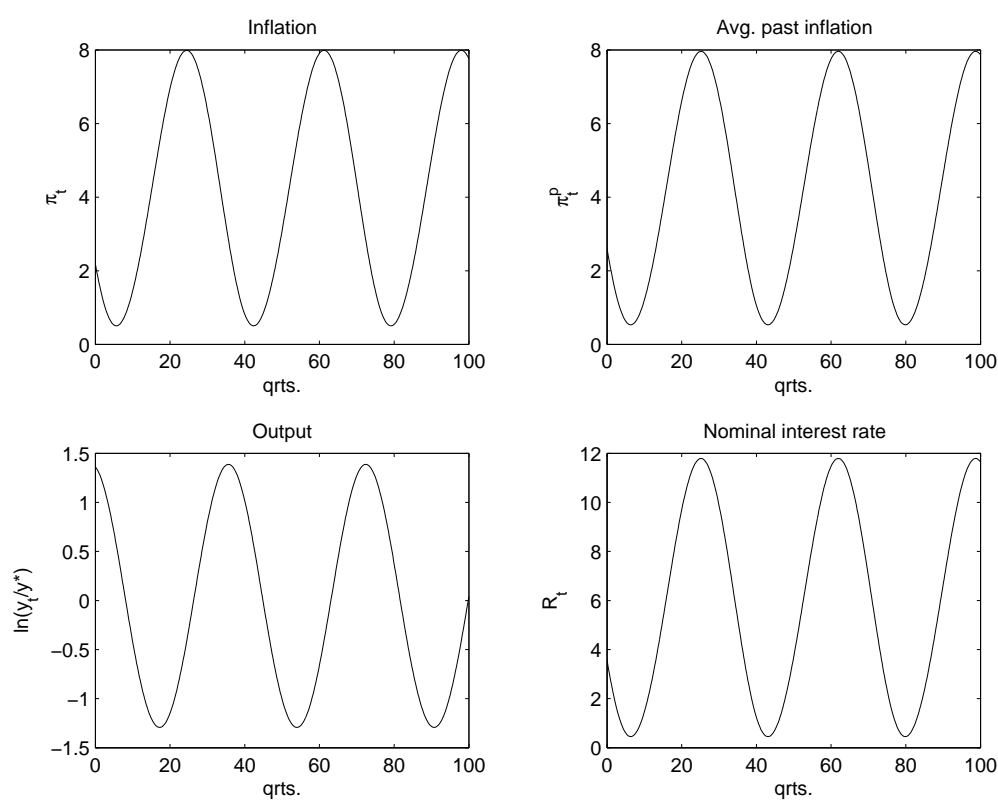

Note: All variables are in percent. Inflation, $\pi_{t}$, and average lagged inflation, $\pi_{t}^{p}$, are expressed in annual rates. The smoothing parameter $b$ is set at 1.3925 (about 9 weeks).

Note that as the target variable $\pi^{p}$ converges to $-\infty$, the instrument $R$ approaches zero from above. We set all parameter values as in table 1 . In particular, we set $R^{*}=0.0147, \pi^{*}=0.0103$, and $D=1.5$, respectively. At the intended steady state, the interest rate rule is active with a slope of 1.5. Because the above rule respects the zero bound on the nominal interest rate, as the target variable $\pi^{p}$ becomes sufficiently small, the policy stance becomes passive $\left(\lim _{\pi^{p} \rightarrow-\infty} \rho^{\prime}\left(\pi^{p}\right)=0\right)$.

As shown in Benhabib, Schmitt-Grohé, and Uribe (2001a), when the interest rate feedback rule respects the zero lower bound, is continuous, and has a slope greater than unity at the target steady state, which is the case for the feedback rule given in (57), then there typically exists a second steady state at which monetary policy is passive and inflation is below the value targeted by the central bank. We refer to this second steady state as the liquidity-trap steady state because the economy is trapped in an equilibrium in which the government fails to achieve its inflation target. For the parameterization considered here the annual inflation rate at the liquidity trap is 0.72 percent, compared to a target rate of inflation of 4.2 percent. The nominal interest rate is 2.46 percent per year whereas at the target steady state it is 6 percent. 
Around the target inflation rate $\pi^{*}$, the exponential interest-rate rule given in equation (57) is identical up to first order to the linear rule given in (35). It follows that the change in functional form preserves the the local stability properties of the economy in the neighborhood of the target steady state and does not affect the existence of the Hopf bifurcation nor the size of $b^{h}$. Thus, under the exponential rule, the economy still undergoes a Hopf bifurcation at $b^{h}=1.4658$. Moreover, for values of $b<b^{h}$ there exists a unique equilibrium converging to the target steady state and for values of $b>b^{h}$ there exists a continuum of such equilibria.

The particular functional form assumed for the feedback rule may affect the criticality of the Hopf bifurcation. However, our calculations show that the first Lyapunov coefficient at $b=b^{h}$ is still negative $\left(l_{1}(0)=-58.2\right)$. It follows that the Hopf bifurcation is supercritical and that, for the arguments presented before, attracting cycles exist for $b<b^{h}$. Again, we use numerical methods to detect these cycles. The upper left panel of figure 5 displays the limit cycle that emerges for a

Figure 5: Two Factor Model and $\rho\left(\pi^{p}\right)=R^{*} e^{D / R^{*}\left(\pi^{p}-\pi^{*}\right)}$
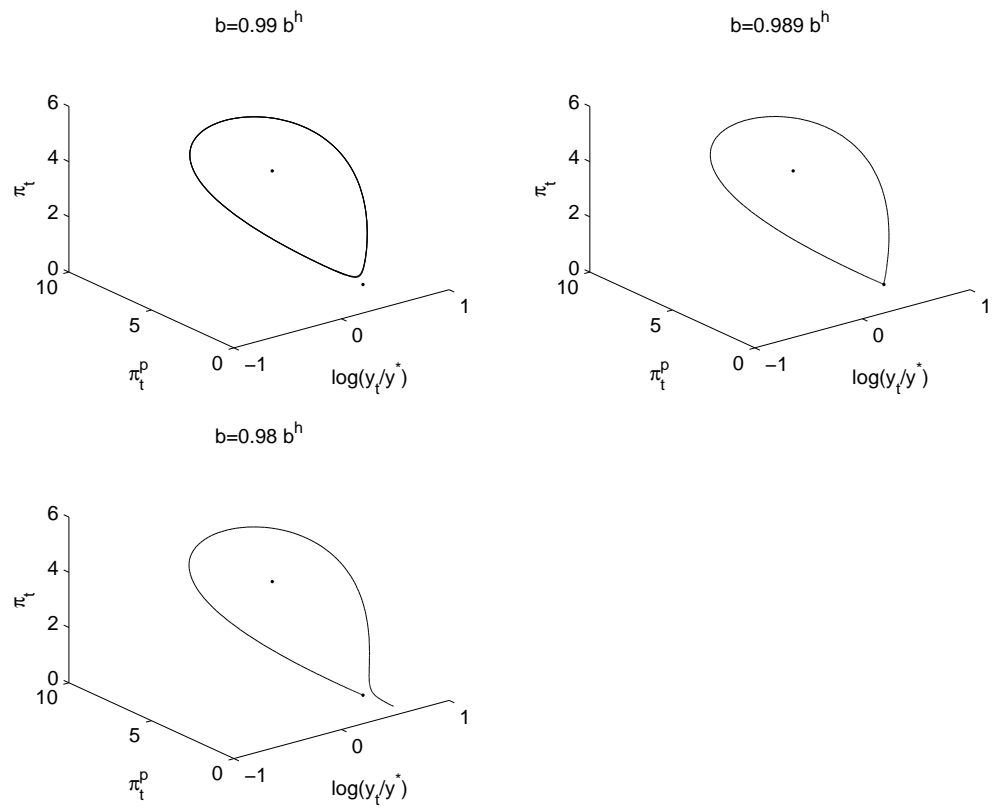

Note: All variables are in percent. Inflation, $\pi_{t}$, and average lagged inflation, $\pi_{t}^{p}$, are expressed in annual rates.

value of $b$ very close to the one at which the Hopf bifurcation takes place. In particular, we set $b=1.45$, so that the average lag of the inflation measure to which the central bank responds is 
about 9 weeks. The cycle is shown with a solid line. Also indicated in the figure are the target steady state and the liquidity trap steady state. The figure reveals that along the cycle the inflation rate never falls down to the level of inflation that prevails in the liquidity trap. Specifically, the lowest value of inflation along the cycle is 1.07 percent per year, whereas inflation at the liquidity trap is 0.72 percent per year. At the same time, output varies from 0.68 percent above trend and 0.66 percent below trend. It takes about 16 years to complete one cycle.

\subsection{Equilibria Converging to the Liquidity Trap}

For values of $b$ below $0.99 \times b^{h}$, i.e., when the average lag length in the central bank's inflation measure exceeds 9 weeks, our numerical tools were unable to detect equilibrium cycles. We conjecture that at some lower value of $b$ the equilibrium cycles are absorbed into a homoclinic orbit. On this homoclinic orbit, the (one-dimensional) unstable manifold associated with the liquidity-trap steady state travels around the target steady state and ends back at the liquidity trap. As we further lower $b$, the homoclinic orbit breaks and is replaced by equilibrium trajectories connecting the target steady-state with the liquidity trap steady state. Such trajectories connecting steady states are known as 'saddle connections.' (See the discussion in section 7 referring to Alexander and Yorke, 1978, as well as the Bogdanov-Takens bifurcation diagram in Kuznetsov, 1998, page 322.) Along these trajectories, the economy can start out in a small neighborhood around the target rate of inflation $\pi^{*}$ and then spiral down into the liquidity trap.

To analyze the existence of a saddle connection, we apply a theorem due to Kopell and Howard (1975). (For a statement of the theorem and other details, see the appendix.) Loosely speaking, this theorem says that if the equilibrium system satisfies a number of conditions at the critical point $\left(b, D, \lambda, \pi, \pi^{p}\right)=\left(b^{h}, 1, \lambda^{*}, \pi^{*}, \pi^{*}\right)$, then around that point the equilibrium displays either endogenous cycles, or a homoclinic orbit, or a saddle connection for values of $(b, D)$ in the neighborhood of $\left(b^{h}, 1\right)$. The conditions of the theorem concern the first and second-order terms of a Taylor series expansion of the system of equilibrium conditions with respect to $\left(b, D, \lambda, \pi, \pi^{p}\right)$ around the critical point. The conditions of the Kopell-Howard theorem are satisfied by the equilibrium conditions of the model for $(b, D)$ in the neighborhood of $\left(b^{h}, 1\right)$, when the other parameters take the values shown in table 1. See the appendix for the sketch of the proof and a discussion.

We were able to identify numerically the existence of attracting endogenous cycles for $D=1.5$ 
and values of $b$ between $0.989 \times b^{h}$ and $b^{h}$. As the top-right panel of figure 5 shows, for $b=0.989 \times b^{h}$, the system features a homoclinic orbit. For values of $b$ below $0.989 \times b^{h}$, the homoclinic orbit breaks open (see the bottom-left panel of figure 5). For these values of $b$ we were unable to numerically identify endogenous cycles. Guided by the Kopell-Howard theorem, we conjecture the existence of saddle connections linking the intended and the liquidity-trap steady states. Moreover, we can numerically rule out that the saddle connection runs from the liquidity trap to the intended steady state. Specifically, if the connection was indeed from the liquidity trap to the intended steady state, then one could place the economy on the saddle path converging to the intended steady staterecall that the stable manifold associated with the intended steady state is one-dimensional - and run time backwards. The resulting trajectory should converge to the liquidity trap. Our numerical analysis suggests, however, that this is not the case.

We conclude that when the central bank follows a backward-looking interest rate rule, then, depending upon how backward-looking the rule is, the competitive equilibrium features one of the following forms of indeterminacy: multiple trajectories converging to the intended steady state, endogenous attracting cycles, a homoclinic orbit, or a saddle connection linking the intended steady state with the liquidity trap. It also follows from the above analysis that for sufficiently backwardlooking interest-rate rules to be conducive to macroeconomic stability, they must be accompanied by trigger policies that are activated in the event that the economy threatens to depart from the desired steady-state. These accompanying policies must have the characteristic of making the liquidity trap unsustainable.

In Benhabib, Schmitt-Grohé, and Uribe (2002b), we propose several fiscal and monetary policies that preserve the appealing features of Taylor rules, such as local uniqueness of equilibrium near the inflation target, and at the same time rule out the deflationary expectations that can lead an economy into a liquidity trap. There, we analyze in detail two types of regimes that succeed in accomplishing this task. One is to enact a fiscal stimulus package should the economy begin to experience persistent deflation. This active fiscal stance must be strong enough to require positive inflation - and thereby a departure from the liquidity trap - to be sustainable. The second trigger policy we propose consists in switching to a money-growth-rate peg when the economy is headed toward the liquidity trap. Switching to a money-growth-rate peg helps avoid the liquidity trap only if accompanied by an appropriate fiscal stance. Christiano and Rostagno (2001) propose to switch 
to the second policy option suggested by Benhabib, Schmitt-Grohé, and Uribe (2002b) as soon as inflation falls only slightly short of its target value. In this way, they hope to be able to avoid not only the liquidity trap equilibrium but also other undesired bounded equilibria not converging to the steady state, such as the endogenous cycles identified in this paper or the chaotic dynamics characterized in Benhabib, Schmitt-Grohé, and Uribe (2002a).

\section{$6 \quad$ Interest Rate Smoothing}

Recently, a growing literature has focused on the empirical and theoretical relevance of interestrate rules that incorporate lagged values of the nominal interest rate as an explicit argument. Sack (1998) estimates this type of rule using U.S. data and finds a statistically significant coefficient on the lagged interest rate of about 0.65 . On theoretical grounds, a number of authors, including Levin, Wieland, and Williams (1999), Rotemberg and Woodford (1999), and Giannoni and Woodford (2002) have suggested that the performance of Taylor rules can be improved by adding lagged values of the nominal interest rate. Moreover, the work of Rotemberg and Woodford and of Giannoni and Woodford suggests that the coefficient on the lagged interest rate should be greater than one. In discrete time, the Taylor rule augmented to allow for a smoothing component takes the form:

$$
R_{t}-R^{*}=\phi\left(R_{t-1}-R^{*}\right)+\theta\left(\pi_{t}-\pi^{*}\right) ; \quad \text { with } \theta, \phi>0 .
$$

We can write the continuous-time version of (58) as

$$
\dot{R}_{t}=-b\left(R_{t}-R^{*}\right)+D b\left(\pi_{t}-\pi^{*}\right) ; \quad \text { with } D b>0 \text {. }
$$

The case in which the smoothing parameter is less than one in the discrete-time version of the rule $(\phi<1)$ corresponds to setting $b>0$ in the continuous-time counterpart, and the case in which the smoothing coefficient is greater than one $(\phi>1)$ requires setting $b<0$.

In the case that the coefficient on the lagged interest rate is less than one $(\phi<1$ in discrete time or $b>0$ in continuous time), the interest-rate rule can be expressed as a backward-looking rule of the type studied earlier in this paper. In effect, integrating (59) from the infinite past to 
the present we obtain

$$
R_{t}=R^{*}+D\left(\pi_{t}^{p}-\pi^{*}\right)
$$

where $\pi_{t}^{p}$ is a weighted average of past inflation rates defined by equation (11). Note that because $b>0$, it must be the case that $D>0$ to ensure that the nominal interest rate depends positively on inflation in the policy rule (59). The above policy rule is identical to (35). It follows that all of the results of the previous sections carry over immediately. In particular, the equilibrium is indeterminate under an active policy stance because either the system displays local indeterminacy or because attracting equilibrium cycles exist, or because a saddle connection exists.

The case in which in the discrete-time version of the Taylor rule the smoothing parameter is greater than unity $(\phi>1)$ is captured in the continuous-time version by restricting $b$ to be negative. This 'superinertial' specification of the policy rule has been advocated by Rotemberg and Woodford and Giannoni and Woodford as optimal. In this case we must set $D<0$ so that the coefficient on inflation in (59) is positive. Using forward integration on (59), we can express the nominal interest rate as a function of a weighted average of future expected inflation rates. This operation yields

$$
R_{t}=D\left(\pi_{t}^{f}-\pi^{*}\right)+R^{*}, \quad \text { with } D<0
$$

where $\pi_{t}^{f}$ is a measure of expected future inflation given by

$$
\pi_{t}^{f} \equiv-b \int_{t}^{\infty} e^{b(s-t)} \pi_{s} d s
$$

Because in the discrete-time case the lagged interest rate is a predetermined variable at time $t$, the interest rate rule (59) puts an equilibrium restriction on the weighted sum of future inflation rates, making $\pi_{t}^{f}$ a predetermined (non jump) variable rather than a free (jump) variable. Differentiating the above expression one obtains $\dot{\pi}_{t}^{f}=b\left(\pi_{t}-\pi_{t}^{f}\right)$. Note that in this case the structure of the system of equilibrium conditions is identical to the one associated with the backward-looking rule, given by equations (23)-(25), with $\pi_{t}^{f}$ taking the place of $\pi_{t}^{p}$, with the linear specification for the policy rule given in (60), and the restrictions $b<0$ and $D<0$. Therefore we can immediately apply the analysis of section 3. In particular, the local stability of equilibrium can be determined by characterizing the eigenvalues of the $3 \times 3$ Jacobian matrix $A$ given in equation (30). The 
determinant of this matrix is $b A_{21}(1-D)<0$, where $A_{21}>0$ is defined by equation (31). Thus, the number of eigenvalues with positive real parts is either zero or two. At the same time, the trace of $A$ is given by $r-b>0$, which indicates the existence of at least one eigenvalue with positive real part. It follows that the system has exactly two eigenvalues with positive real parts. Because the reduced form of the equilibrium conditions involves two jump variables $(\lambda$ and $\pi$ ) and one non jump variable $\left(\pi^{f}\right)$, it follows that the equilibrium is everywhere locally determinate and no Hopf bifurcation exists. It is worth noting that when $b$ is negative local uniqueness and the absence of a Hopf bifurcation obtain even if $D$ is positive (as long as it does not exceed unity) and irrespectively of whether the interest rate rule responds actively $(D b>1)$ or passively $(D b<1)$ to changes in current inflation. ${ }^{14}$ Also, the interest-rate rule requires that the monetary authority respond by increasing the nominal interest rate in response to short-term increases in inflation-as reflected by a positive inflation coefficient in equation (59) — and by decreasing the interest rate in response to long-run increases in inflation — as reflected by a negative inflation coefficient in equation (60).

\section{Discussion and Conclusion}

A question that emerges naturally from our findings concerns the way in which the location and shape of the equilibrium cycles identified in this paper change as one varies the deep structural parameters of the model. Of particular interest are variations in the average lag-length of the inflation measure to which the central bank responds. A partial answer to the issue of robustness of our central result is given by the sensitivity analysis performed in section 4.4. But, as the analysis in section 5 makes clear, more general theoretical results exists. The cycles that emerge from a Hopf bifurcation - like steady states - will change as we vary parameters globally (see Alexander and Yorke, 1978). Under some regularity conditions, they will not disappear into the thin air but they can: (a) go out of the domain of definition of endogenous variables; (b) can close upon themselves via another distinct Hopf bifurcation; or (c) their amplitude can go to infinity. In case (a), if, for example, some non-negativity constraints become binding, then studying the dynamics properly would require incorporating the constraints into the analysis. Case (b) would be detectable in our analysis since the conditions for a second Hopf bifurcation would be observed from the linear

\footnotetext{
${ }^{14}$ When $D$ is greater than one and $b$ is negative, then the equilibrium is either locally indeterminate or does not exist.
} 
dynamics. We can indeed rule out this case, for we have shown in Proposition 4.1 that in our model the Hopf bifurcation is unique. Case (c) which may involve the absorption of the cycle by a homoclinic orbit, can result in more complex dynamics. The saddle connection characterized in section 5.1 is just one example of such dynamics.

In the baseline economy of section 2 , where output was produced with real balances as the sole input, we were able to identify numerically the existence of attracting cycles for average lag lengths in the Taylor rule of about 1.5 months. In the more realistic economy of section 5 , where the production technology allowed for both real money balances and labor services as factor inputs, cycles were detected for average lag lengths in the cental bank's moving average of inflation of over nine weeks. It follows from the results of Alexander and Yorke (1978) that the fact that we were not able to numerically detect cycles for longer policy lags does not necessarily imply that such cycles do not exist in that region of the parameter space.

We close the paper by taking stock of our findings and placing them in perspective. A number of studies, most notably Bernanke and Woodford (1997), Carlstrom and Fuerst (2000a,b) and Benhabib, Schmitt-Grohé, and Uribe (2001b), have stressed the perils of interest-rate feedback rules whereby the interest rate responds to forecasts of future inflation. It has been emphasized in particular that such rules may give rise to aggregate instability in the form of self-fulfilling expectations. One response to this problem has been to postulate rules featuring a weighted average of past observed inflation rates as the measure of inflation to which the central bank responds. For example, Carlstrom and Fuerst (2000a) conclude that to ensure uniqueness of the rational expectations equilibrium the central bank should react aggressively to past inflation rates. In analyzing the stabilizing properties of backward-looking interest-rate rules, the literature extant has limited attention to the study of equilibria in a small neighborhood around the steady state in which all endogenous variables are expected to converge asymptotically to the steady state.

In this paper we consider a larger class of equilibria. Namely, equilibria in which the economy can diverge from the steady-state and be attracted to a limit cycle. Our central result is that endogenous equilibrium cycles exist under backward-looking interest rate rules. The existence of a limit cycle necessarily implies the indeterminacy of equilibrium. For any trajectory originating in a certain, relatively large neighborhood of the limit cycle - including any arbitrarily small neighborhood around the steady state - will converge to the cycle itself. This type of indeterminacy opens 
the door to aggregate fluctuations driven solely by changes in agents' expectations about the future path of the economy. This means that the mere introduction of a backward-looking component into interest-rate policy is not sufficient to guarantee aggregate stability.

The results described above are disconcerting, as they suggest that a policy rule commonly believed to be stabilizing can in fact be destabilizing. But the paper also provides constructive findings for the design of monetary policy. Interest-rate rules whereby, in addition to current inflation, the central bank responds aggressively to the lagged interest rate are shown to ensure that the inflation target is locally the unique equilibrium and that no bifurcations exist. For this result to hold it is required that the coefficient on the past value of the interest rate in the Taylor rule be greater than unity. That is, the feedback rule must be superinertial. If that coefficient is positive but less than one, then equilibrium cycles continue to exist. Rotemberg and Woodford (1999) and Giannoni and Woodford (2002) have also found that interest-rate feedback rules with a coefficient greater than one on past interest rates deliver a unique equilibrium. Moreover, these papers find that such rules are indeed optimal. Our findings can be viewed as an extension of their analysis in two important respects. First, their work is limited to equilibria where all endogenous variables are expected to converge asymptotically to the steady state. Second, those papers do not allow for a cost channel in the transmission of monetary policy. Therefore, our paper demonstrates that the result that a coefficient greater than one on the lagged interest rate is stabilizing applies more generally and to a richer class of economic environments than previously studied.

\section{Appendix}

Theorem 7.1 (Kopell and Howard, 1975, combines Theorem 7.1 and Corollary 7.1) Let $\dot{X}=F_{\mu, \nu}(X)$ be a two-parameter family of ordinary differential equations on $R^{n}, F$ smooth in all of its arguments, such that $F_{\mu, \nu}(0)=0$. Using a Taylor expansion $\dot{X}=F_{\mu, \nu}(X)$ can be written

$$
\dot{X}=\left(A+\mu A_{1}+\nu A_{2}\right) X+Q(X, X)+R_{1}(X, \mu, \nu)
$$

where $A, A_{1}, A_{2}$ are $n \times n$ matrices, the vector $Q(X, X)$ contains the terms quadratic in $x_{i}$ and is independent of $(\mu, \nu)$, and $R_{1}(X, \mu, \nu)=o\left(\mu x_{i}, \nu x_{i}, x_{i} x_{j}\right)$. 


\section{Also assume:}

1. $d F_{0,0}(0) \equiv A$ has a double zero eigenvalue corresponding to a single eigenvector $e$.

2. The mapping $(\mu, \nu) \rightarrow\left(\right.$ det $\left.d F_{\mu, \nu}(0), \sigma\left(d F_{\mu, \nu}(0)\right)\right)$ has a nonzero Jacobian at $(\mu, \nu)=(0,0)$, where $\sigma\left(d F_{\mu, \nu}(0)\right)$ is the sum of the principal minors of $d F_{\mu, \nu}(0)$.

3. $\left[d F_{(0,0)}(0), Q(e, e)\right]$ has rank $n$.

Then there is a curve $f(\mu, \nu)=0$ such that if $f\left(\mu_{0}, \nu_{0}\right)=0$, then $\dot{X}=F_{\mu_{0}, \nu_{0}}(X)$ has a homoclinic orbit. This one-parameter family of homoclinic orbits (in $(X, \mu, \nu)$ space) is on the boundary of a two-parameter family of periodic solutions. For all $|\mu|,|\nu|$ sufficiently small, if $\dot{X}=F_{\mu, \nu}(X)$ has neither a homoclinic orbit nor a periodic solution, there is a unique trajectory joining the critical points.

It is straightforward to check that the theorem above applies to our system (12), (52), and (53) with parameters $(\mu, \nu)=\left(b-b^{h}, D-1\right)$. First we note that the steady state of our system is independent of the parameters $(b, D)$, as required by the theorem. Assumption (1) is satisfied at parameter values $\left(b, D, \lambda, \pi, \pi^{p}\right)=\left(b^{h}, 1, \lambda^{*}, \pi^{*}, \pi^{*}\right)$. To see this note that at $D=1, b=b^{h}$, and $r \neq b$, by construction, the roots of the Jacobian corresponding to the system (12), (52), and (53) must be $(0,0, r-b)$, irrespective of other parameters. This is because given $b=b^{h}$, there is always a pair of roots that sum to zero (they could be real or pure imaginary). The proof is given by Orlando's formula in Gantmacher (1960), page 196. The sum of the roots is the trace, $r-b$, which means the third root is $r-b$. Finally, the determinant is singular because the first row is $(0,1,-1)$ and the third row is $(0, b,-b)$, which means that the two roots that add up to zero must in fact be real and equal to zero. Conditions (2.) and (3.) are full rank conditions, which will hold generically over the parameter space. We checked that they also hold for the particular calibration of section 5; numerical computations are available upon request. We should note that the theorem is valid for $\left|b-b^{h}\right|,|D-1|$ sufficiently small, so that the numerical analysis that we provided in section 5 is necessary to establish the existence of the cycles, the homoclinic orbit and the saddle connection in the neighborhood of our calibrated values of $b$ and $D$. An alternative approach to establish the saddle connection and cycles in three dimensional systems, once the existence of a homoclinic orbit can be ascertained, is that of Shil'nikov: see Kuznetsov (1998), pages 213-225. 


\section{References}

Alexander, J. C. and James A. Yorke, "Global Bifurcations of Periodic Orbits," American Journal of Mathematics, Vol. 100, No. 2, Apr., 1978, 263-292.

Ball, Laurence, "Short-Run Money Demand," October 2002, NBER Working Paper 9235.

Barth, Marvin J. and Valerie Ramey "The Cost Channel of Monetary Transmission" In NBER Macroeconomics Annual 2001, edited by Ben Bernanke and Kenneth Rogoff, Cambridge, MA: MIT Press, 2002, p. 199-239.

Basu, Susanto and John G. Fernald, "Returns to scale in U.S. production: Estimates and implications," Journal of Political Economy, 105, 1997, 249-283.

Benhabib, Jess, Stephanie Schmitt-Grohé, and Martín Uribe, "Appendix to 'Monetary Policy and Multiple Equilibria'," March 13, 2000, Unpublished Manuscript, Rutgers University [available at http://econweb.rutgers.edu/grohe].

Benhabib, Jess, Stephanie Schmitt-Grohé, and Martín Uribe, "The Perils of Taylor Rules," Journal of Economic Theory, 96, January-February 2001a, 40-69.

Benhabib, Jess, Stephanie Schmitt-Grohé, and Martín Uribe, "Monetary Policy and Multiple Equilibria," American Economic Review, 91, March 2001b, 167-186.

Benhabib, Jess, Stephanie Schmitt-Grohé, and Martín Uribe, "Chaotic Interest Rate Rules," American Economic Review Papers and Proceedings, 92, May 2002a, 72-78.

Benhabib, Jess, Stephanie Schmitt-Grohé, and Martín Uribe, "Avoiding Liquidity Traps," Journal of Political Economy, 110, June 2002b, 535-563.

Bernanke, Ben and Michael Woodford, "Inflation forecasts and monetary policy," Journal of Money Credit and Banking, 29, 1997, 653-684.

Calvo, Guillermo A., "On Models of Money and Perfect Foresight," International Economic Review, 29, February 1979, 83-103.

Carlstrom, Charles T. and Timothy S. Fuerst, "Forward-Looking Versus Backward-Looking Taylor Rules," FRB Cleveland Working Paper 0099, 2000a.

Carlstrom, Charles T. and Timothy S. Fuerst, "The Role of Investment Spending in Sticky Price Models," FRB Cleveland Working Paper, 2000b.

Carlstrom, Charles T. and Timothy S. Fuerst, "Timing and Real Indeterminacy in Monetary Mod- 
els," Journal of Monetary Economics, 47, April 2001, 285-98.

Christiano, Lawrence J. and Rostagno, Massimo, "Money Growth Monitoring and the Taylor Rule," Manuscript. Evanston: Northwestern University, June 23, 2001.

Clarida, Richard, Jordi Gali and Mark Gertler, "The Science of Monetary Policy: A New Keynesian Perspective," Journal of Economic Literature, 37, December 1999, 1661-1707.

Dupor, William D., "Investment and Interest Rate Policy," Journal of Economic Theory, 98, May 2001, 85-113.

Fischer, Stanley, "Money and the Production Function," Economic Inquiry, 12, December 1974, $517-33$.

Friedman, Benjamin M., "Monetary Policy Without Quantity Variables," American Economic Review, 78, May 1988a, 440-445.

Friedman, Benjamin M., "Lessons On Monetary Policy From the 1980s," Journal of Economic Perspectives, 2, Summer 1988b, 51-72.

Friedman, Milton, A Program for Monetary Stability, Fordham University Press New York, 1960.

Gantmacher, F. R., The Theory of Matrices, New York: Chelsea, 1960.

Giannoni, Marc and Michael Woodford, "Optimal Interest Rate Rules: II. Applications," mimeo, Princeton University, August 26, 2002.

Kopell, N. and L. N. Howard, "Bifurcations and trajectories joining critical points," Advances in Mathematics, 18, 1975, 306-358.

Kuznetsov, Yuri A., Elements of Applied Bifurcation Theory, Second Edition, New York: Springer Verlag, 1998.

Leeper, Eric, "Equilibria under 'Active' and 'Passive' Monetary and Fiscal Policies," Journal of Monetary Economics, 27, 1991, 129-147.

Levin, Andrew, Volker Wieland, and John Williams "Robustness of Simple Policy Rules Under Model Uncertainty" In Monetary Policy Rules, edited by John B. Taylor, NBER Conference Report series. Chicago and London: University of Chicago Press, 1999, 263-99.

Loyo, Eduardo, "Tight Money Paradox on the Loose: A Fiscalist Hyperinflation," manuscript, Harvard University, 1999.

Mulligan, Casey B., "Scale Economies, the Value of Time, and the Demand for Money: Longitudinal Evidence from Firms," Journal of Political Economy, 105, October 1997, 1061-1079. 
Rotemberg, Julio J., "Sticky Prices in the United States," Journal of Political Economy, 90, 1982, $1187-1211$.

Rotemberg, Julio and Woodford, Michael "Interest-Rate Rules in an Estimated Sticky-Price Model" In Monetary Policy Rules, edited by John B. Taylor, University of Chicago Press, 1999.

Sack, Brian, "Uncertainty, Learning, and Gradual Monetary Policy," Board of Governors of the Federal Reserve System, Finance and Economics Discussion Paper Series: 98-34, July 1998.

Sbordone, Argia, "Prices and unit labor costs: A new test of price stickiness," Journal of Monetary Economics, 49, 2002, 265-292.

Schmitt-Grohé, Stephanie and Martín Uribe, "Price Level Determinacy and Monetary Policy Under a Balanced-Budget Requirement," Journal of Monetary Economics , 45, February 2000a, 211246.

Schmitt-Grohé, Stephanie and Martín Uribe, "Liquidity Traps with Global Taylor Rules," manuscript. Philadelphia: University of Pennsylvania, July 2000b. [available at http://www.econ.upenn.edu/ uribe.]

Stock, James H. and Mark W. Watson, "A Simple Estimator of Cointegrating Vectors in Higher Order Integrated Systems," Econometrica, 61, 1993, 783-820.

Taylor, John B., "Conditions for Unique Solutions in Stochastic Macroeconomic Models with Rational Expectations," Econometrica, 45, 1977, 1377-1385.

Taylor, John B., "Discretion versus rules in practice," Carnegie-Rochester Series on Public Policy, 39, 1993, 195-214.

Taylor, John B., "The robustness and efficiency of monetary policy rules as guidelines for interest rate setting by the European Central Bank," mimeo, Stanford University, 1998. 